\title{
Spatial and temporal variations in glacier aerodynamic surface roughness during the melting season, as estimated at the August-one ice cap, Qilian mountains, China
}

\author{
Junfeng Liu, Rensheng Chen, and Chuntan Han \\ Qilian Alpine Ecology and Hydrology Research Station, Key Laboratory of Ecohydrology of Inland River Basin, Northwest \\ Institute of Eco-Environment and Resources, Chinese Academy of Sciences, Lanzhou, China
}

Correspondence: Rensheng Chen (crs2008@1zb.ac.cn)

Received: 6 August 2019 - Discussion started: 17 September 2019

Revised: 14 January 2020 - Accepted: 10 February 2020 - Published: 16 March 2020

\begin{abstract}
The aerodynamic roughness of glacier surfaces is an important factor governing turbulent heat transfer. Previous studies rarely estimated spatial and temporal variation in aerodynamic surface roughness $\left(z_{0}\right)$ over a whole glacier and whole melting season. Such observations can do much to help us understand variation in $z_{0}$ and thus variations in turbulent heat transfer. This study, at the August-one ice cap in the Qilian mountains, collected three-dimensional ice surface data at plot scale, using both automatic and manual close-range digital photogrammetry. Data were collected from sampling sites spanning the whole ice cap for the whole of the melting season. The automatic site collected daily photogrammetric measurements from July to September of 2018 for a plot near the center of the ice cap. During this time, snow cover gave way to ice and then returned to snow. $z_{0}$ was estimated based on micro-topographic methods from automatic and manual photogrammetric data. Manual measurements were taken at sites from the terminals to the top of the ice cap; they showed that $z_{0}$ was larger at the snow and ice transition zone than in areas that are fully snow or ice covered. This zone moved up the ice cap during the melting season. It is clear that persistent snowfall and rainfall both reduce $z_{0}$. Using data from a meteorological station near the automatic photogrammetry site, we were able to calculate surface energy balances over the course of the melting season. We found that high or rising turbulent heat, as a component of surface energy balance, tended to produce a smooth ice surface and a smaller $z_{0}$ and that low or decreasing turbulent heat tended to produce a rougher surface and larger $z_{0}$.
\end{abstract}

\section{Introduction}

The roughness of ice surfaces is an important control on air-ice heat transfer, on the ice surface albedo, and thus on the surface energy balance (Greuell and Smeets, 2001; Hock and Holmgren, 2005; Irvine-Fynn et al., 2014; Steiner et al., 2018). The snow and ice surface roughness at centimeter and millimeter scales is also an important parameter in studies of wind transport, snowdrifts, snowfall, snow grain size and ice surface melt (Denby and Smeets, 2000; Brock et al., 2006; McClung and Schaerer, 2006; Fassnacht et al., 2009a, b). Radar sensor signals, such as Synthetic Aperture Radar (SAR) (Oveisgharan and Zebker, 2007), altimeters and scatter meters, are also affected by ice and snow surface roughness (Lacroix et al., 2007, 2008). One of the most important of these influences is the aerodynamic roughness of $z_{0}$, which is related to ice surface topographic roughness in a complex way (Andreas, 2002; Lehning et al., 2002; Smith, 2014; Smith et al., 2016). Determination of $z_{0}$ based on topographic roughness is therefore of great interest for energy balance studies (Greuell and Smeets, 2001).

Glacier surface $z_{0}$ has been widely studied through methods such as eddy covariance (Munro, 1989; Smeets et al., 2000; Smeets and Van den Broeke, 2008; Fitzpatrick et al., 2019) or wind profiling (Wendler and Streten, 1969; Greuell and Smeets, 2001; Denby and Snellen, 2002; Miles et al., 2017; Quincey et al., 2017). However, micro-topographic estimated $z_{0}$ shows some advantages, such as lower scatter compared to profile measurements over slush and ice (Brock et al., 2006), and ease of application at different locations (Smith et al., 2016). Current research has increasingly used 
the micro-topographic method to estimate $z_{0}$. It has also become clear that it is important to estimate $z_{0}$ over the entire course of the melting season and at many points on the glacier surface, as $z_{0}$ is prone to large spatial and temporal variation (Brock et al., 2006; Smeets and Van den Broeke, 2008). This variation is due to variations in weather and snowfall (Albert and Hawley, 2002). The micro-topographic estimated $z_{0}$ allows repeated measurement at many points on the glacier surface, which is not possible with wind profile or eddy covariance methods.

Photogrammetry has been increasingly popular as a method to measure the aerodynamic surface roughness of snow and ice (Irvine-Fynn et al., 2014; Smith et al., 2016; Miles et al., 2017; Quincey et al., 2017; Fitzpatrick et al., 2019). Initially, the micro-topographic method was developed because snow digital photos were taken against a dark background plate. The contrast between the surface photo and the plate could then be quantified as a measure of glacier roughness (Rees, 1998). This method is still widely applied for quantifying glacier surface roughness (Rees and Arnold, 2006; Fassnacht et al., 2009a, b; Manninen et al., 2012). A more recent method, as described by Irvine-Fynn et al. (2014), uses modern consumer-grade digital cameras to do close-range photogrammetry at plot scale (small plots of only a few square meters). Appropriate image settings and acquisition geometry allow the collection of high-resolution data (Irvine-Fynn et al., 2014; Rounce et al., 2015; Smith et al., 2016; Miles et al., 2017; Quincey et al., 2017). Such data facilitates the distributed parameterization of aerodynamic surface roughness over glacier surfaces (Smith et al., 2016; Miles et al., 2017; Fitzpatrick et al., 2019). Precision of micro-topographic estimated $z_{0}$ also became a major concern, and many comparative studies with the aerodynamic method (eddy covariance or wind towers measurements) were carried out over debris-covered or non-debriscovered glaciers. The difference was within an order of magnitude for some studies (Fitzpatrick et al., 2019) or strongly correlated (Miles et al., 2017).

Previous researchers have performed some long-term systematic studies of glacier surfaces (Smeets et al., 1999; Brock et al., 2006; Smeets and Van den Broeke, 2008; Smith et al., 2016). The current study applied such methods to the study of snow and ice aerodynamic surface roughness during the melting season at the August-one ice cap. We used both automatic digital photogrammetry and manual photogrammetry. Automatic methods allowed us to monitor daily variations in aerodynamic surface roughness, and manual methods allowed us to characterize aerodynamic surface roughness variation along the main glacial flow line. We also recorded meteorological observations in order to study the impact of weather conditions (e.g., snowfall or rainfall) on aerodynamic surface roughness. This data allowed a further effort to characterize variation in plot-scale $z_{0}$ from an energy balance perspective.

\section{Data and methods}

\subsection{Study area and meteorological data}

The August one glacier ice cap is located in the middle of Qilian Mountains on the northeastern edge of the Tibetan Plateau (Fig. 1a, b). The glacier is a flat-topped ice cap that is approximately $2.3 \mathrm{~km}$ long and $2.4 \mathrm{~km}^{2}$ in area. It ranges in elevation from 4550 to $4820 \mathrm{~m}$ a.s.l. (Guo et al., 2015). This study was conducted during the melting season of 2018, a season characterized by high precipitation. Energy balance analysis indicated that net radiation contributes $86 \%$ and turbulent heat fluxes contribute about $14 \%$ to the energy budget in the melting season. A sustained period of positive turbulent latent flux exists on the August one ice cap in August, causing faster melt rate in this period (Qing et al., 2018).

Researchers had access to meteorological data that had been recorded continuously since September 2015, when an automatic weather station (AWS) was sited at the top of the ice cap (Table 1). The AWS measures air temperature, relative humidity and wind speed at 2 and $4 \mathrm{~m}$ above the surface. Air pressure, incoming and reflected solar radiation, incoming and outgoing longwave radiation, and glacial surface temperature (using an infrared thermometer) are measured at $2 \mathrm{~m}$ height. Mass balance is measured by a Campbell Scientific ultrasonic depth gauge (UDG) close to the AWS. An all-weather precipitation gauge adjacent to the AWS measures solid and liquid precipitation. All sensors sample data every $15 \mathrm{~s}$. Half-hourly means are stored on a data logger (CR1000, Campbell, USA). Throughout the entire melting season (from June to September) researchers periodically checked the AWS station to make sure that it remained horizontal and in good working order. During the entire study period, precipitation total was $261.3 \mathrm{~mm}$, as measured at the AWS. Of this precipitation, $172.1 \mathrm{~mm}$ was snow or sleet and $89.2 \mathrm{~mm}$ was rainfall (Fig. 7a).

\subsection{Automatic photogrammetry}

The study began with the placement of an automatic close range photogrammetry measurement apparatus in the middle of the ice cap $\left(4700 \mathrm{~m} ; 39^{\circ} 1.1^{\prime} \mathrm{N}, 98^{\circ} 53.4^{\prime} \mathrm{E}\right.$; see Figs. $1 \mathrm{~b}$ and 2). It was placed near the existing meteorological station. This was done on 10 July 2018. A wooden frame, $1.5 \mathrm{~m}$ wide and $2 \mathrm{~m}$ long, was put on the ice surface. This frame served as a geo-reference control field (Fig. 3a). Four feature points demarcated the control field; three additional points served as checkpoints. A Canon EOS 1300D cameras, with an image size of $5184 \times 3456$ pixels was connected to the frame. The camera lens was set in wide-angle mode (focal length of $27 \mathrm{~mm}$ ). The $f$ stop was fixed at $f 25$ with an exposure time of $1 / 320 \mathrm{~s}$. The camera was programmed to automatically take seven pictures over a period of $10 \mathrm{~min}$. The photography was repeated at $3 \mathrm{~h}$ intervals from 09:00 to 18:00, Beijing time. During the $10 \mathrm{~min}$ photography periods, the camera 


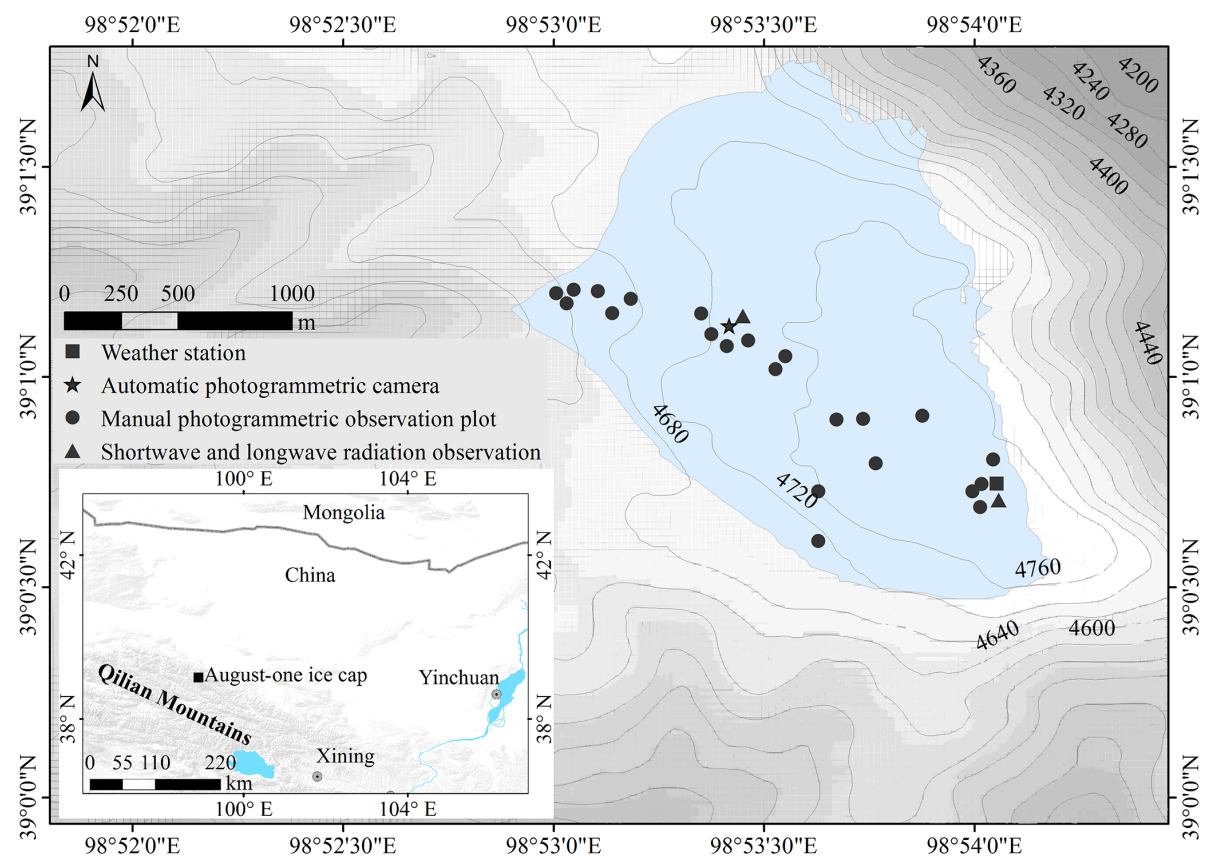

Figure 1. Location of ice cap and study sites. (a) Location of the August-one glacier. (b) Locations of the AWS, automatic and manual photogrammetry plots, and shortwave observation platforms.

Table 1. Measurement specifications for the AWS located at the top of the glacier $(4820 \mathrm{~m}$ a.s.1.). The heights indicate the initial sensor distances to the glacier surface; the actual distances are derived from the SR50A sensor.

\begin{tabular}{llll}
\hline Variable & Sensors & Stated accuracy & Initial height $(\mathrm{m})$ \\
\hline Air temperature & Vaisala HMP 155A & $\pm 0.2^{\circ} \mathrm{C}$ & 2,4 \\
Relative humidity & Vaisala HMP 155A & $\pm 2 \%$ & 2,4 \\
Wind speed & Young 05103 & $\pm 0.3 \mathrm{~m} \mathrm{~s}^{-1}$ & 2,4 \\
Wind direction & Young 05103 & $\pm 0.3^{\circ}$ & 2,4 \\
Ice temperature & Apogee SI-11 & $\pm 0.2^{\circ} \mathrm{C}$ & 2 \\
Shortwave radiation & Kipp\&Zonen CNR-4 & $\pm 10 \% \mathrm{~d}$ total & 2 \\
Longwave radiation & Kipp\&Zonen CNR-4 & $\pm 10 \% \mathrm{~d}$ total & 2 \\
Surface elevation changes & Campbell SR50A & $\pm 0.01 \mathrm{~m}$ & 2 \\
Precipitation & OTT Pluvio & $\pm 0.1 \mathrm{~mm}$ & 1.7 \\
\hline
\end{tabular}

moved along a $1.5 \mathrm{~m}$ long slider rail. The camera was $1.7 \mathrm{~m}$ above the ice surface and moved along the control frame. The seven pictures taken during this period were merged to produce a picture of ice surface topography at millimeter scale (Fig. 3b). This apparatus took pictures over a period of 3 months (12 July to 15 September, the melting season). A total of $64 \mathrm{~d}$ of data were recorded. Each daily photography series produced four sets of pictures $(12 \mathrm{~h}$ and $3 \mathrm{~h}$ intervals). The best-exposed photo sets were manually selected and used as that day's data. We also set up instrumentation to record incoming and reflected solar radiation. Samples were taken every $15 \mathrm{~s} ; 10$ min means were stored on a data logger (CR800, Campbell, USA) located at a height of $1.5 \mathrm{~m}$. Surface elevation changes caused by accumulation and ablation were measured by a digital infrared hunting video camera, which took pictures of ice surface gauge stakes located near the automatic photogrammetry site.

\subsection{Manual photogrammetry}

Manual close-range photogrammetry was used to survey glacier surfaces at several different locations of the ice cap. Observations were made on $4 \mathrm{~d}$ : 12 and 25 July and 3 and 28 August. It should be noted that when the July measurements were performed, the ice cap surface was partially snow covered.

Channels account for only a small portion of the glacier surface area. These surfaces show extreme variability of $z_{0}$ (Rippin et al., 2015; Smith et al., 2016). For that reason, we distributed the manual photogrammetry study sites over the glacier surface in such a way as to cover most surface 


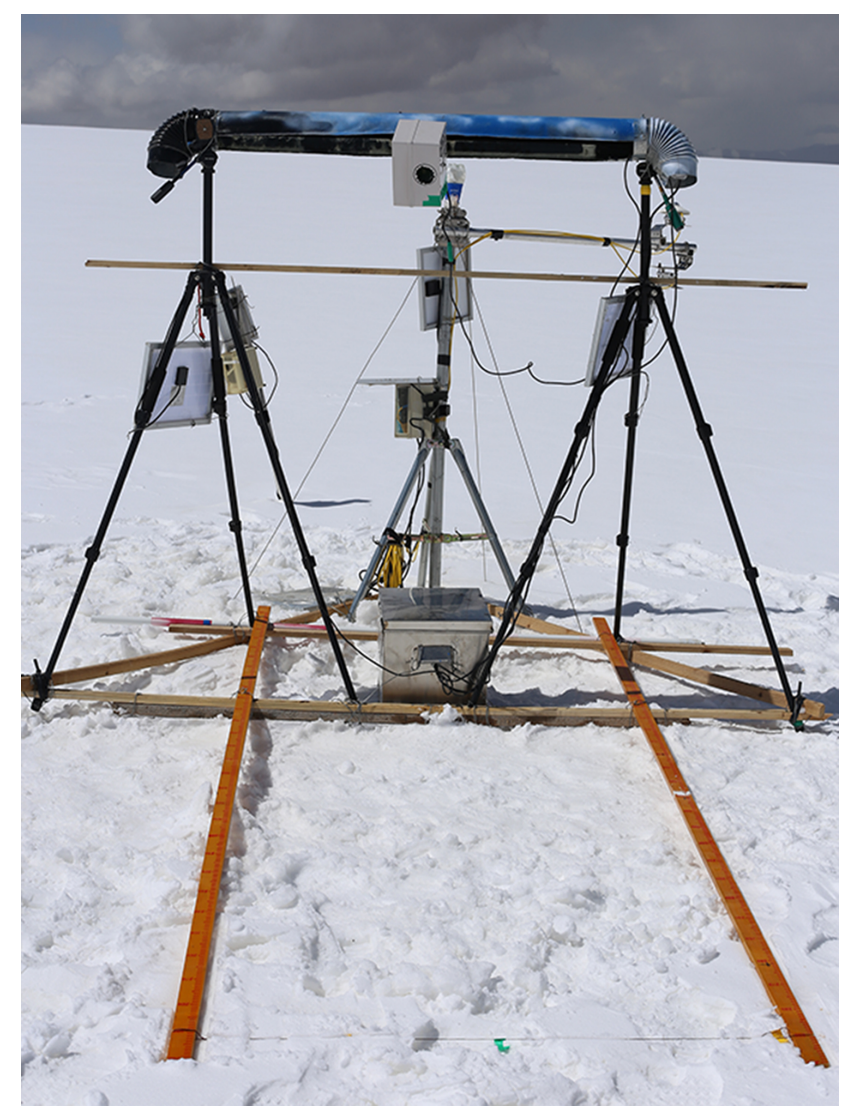

Figure 2. The automatic photogrammetry device at the August one ice cap.

types and topographic regions without including any channels (Fig. 1b). We photographed a total of 36 sites over the $4 \mathrm{~d}$ of observation.

Study plots were demarcated with a $1.1 \times 1.1 \mathrm{~m}$ portable square aluminum frame. A geo-reference of the point cloud was enabled using control points established by eight crossshaped screws on the aluminum frame (Fig. 3c). Photos (convergent photographs, low oblique photos in which camera axes converge toward one another) were taken at $\sim 1.6 \mathrm{~m}$ distances, covering an area of $\sim 1.75 \mathrm{~m}^{2}$. A total of 7 to 12 of such photos were taken at each survey site and surrounded the target area from different directions. The camera used was an EOS 6D $50 \mathrm{~mm}$, with a fixed focal lens and an image size of $5472 \times 3648$ pixels. The $f$ stop was fixed at $f 22$ with an exposure time from $1 / 25$ to $1 / 125 \mathrm{~s}$.

\subsection{Data processing}

Structure-from-motion photogrammetry is revolutionizing the collection of detailed topographic data (Westoby et al., 2012; James et al., 2017). High-resolution DEMs produced from photographs acquired with consumer cameras need careful handling (James and Robson, 2014). In this study, both manual and automatically derived photographs were imported into a software program, Agisoft Photoscan Professional 1.4.0. This software allowed us to estimate camera intrinsic parameters, camera positions, and scene geometry. Agisoft Photoscan Professional is a commercial package, which implements all stages of photogrammetric processing (James et al., 2017). It has previously been used to generate three-dimensional point clouds and digital elevation models of debris-covered glaciers (Miles et al., 2017; Quincey et al., 2017; Steiner et al., 2018), ice surfaces and braided meltwater rivers (Javernick et al., 2014; Smith et al., 2016). In our study, we found that after new snowfall it was difficult to match feature points in the photo sets. A total of $3 \mathrm{~d}$ of automatic data could not be processed. We estimated $z_{0}$ data for the missing days based on data from snowfall days at the automatic site.

\subsection{Aerodynamic roughness estimation}

Methods for measuring roughness at plot scale were first developed by soil scientists (Dong et al., 1992; Smith, 2014). Metrics such as the random roughness (RR) or root-meansquare height deviation $(\sigma)$, the sum of the absolute slopes $(\Sigma S)$, the microrelief index (MI) and the peak frequency (the number of elevation peaks per unit transect length) were used. Later these roughness indices were used to describe snow or ice surface roughness (Rees and Arnold, 2006; Fassnacht et al., 2009b; Irvine-Fynn et al., 2014).

Current photogrammetry methods produce highresolution three-dimensional topographic data. Earlier two-dimensional profile-based methods for estimating surface roughness discard much of the potentially useful three-dimensional topographic data (Passalacqua et al., 2015). Smith et al. (2016) were able to use Eq. (1), developed by Lettau (1969), to make better use of the topographic data, using multiple point clouds and digital elevation models (DEMs). Fitzpatrick et al. (2019) also developed two methods for the remote estimation of $z_{0}$ by utilizing lidar-derived DEM. In this method, $z_{0}$ is quantified as follows:

$z_{0}=0.5 h^{*} \frac{s}{S}$,

where $h^{*}$ represents the effective obstacle height (m) and is calculated as the average vertical extent of microtopographic variations, $s$ is the silhouette area facing upwind $\left(\mathrm{m}^{2}\right), S$ is the unit ground area occupied by microtopographic obstacles $\left(\mathrm{m}^{2}\right)$ and 0.5 is an averaged drag coefficient.

Based on the work of Lettau (1969), Munro (1989) simplified Eq. (1) by assuming that $h^{*}$ can equal twice the standard deviation of elevations in the de-trended profile, with the profile's mean elevation set to $0 \mathrm{~m}$. The aerodynamic roughness length for a given profile then becomes

$z_{0}=\frac{f}{X}\left(\sigma_{\mathrm{d}}\right)^{2}$, 


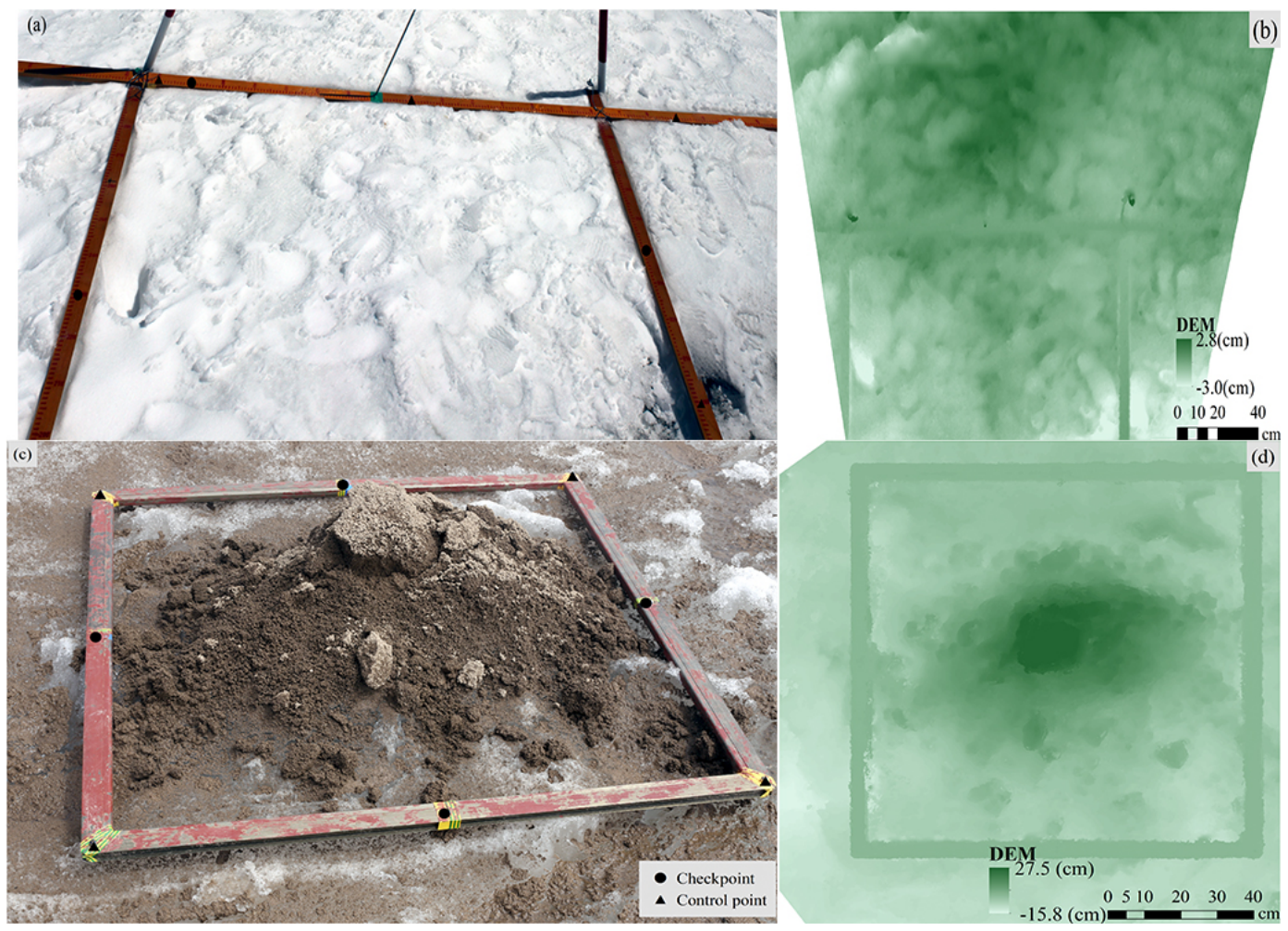

Figure 3. Frames used for automatic and manual photogrammetry. (a) Wooden frame in situ set up for automatic photogrammetry; four control points and three checkpoints are shown on the frame. (b) Detrended DEM for the corresponding snow surface of (a). (c) Manual observation plot, with the four control points and four checkpoints shown on the aluminum frame. Ice surface hummock was covered with cryoconites. (d) Detrended DEM for the corresponding cryoconite surface of (c).

where $f$ is the number of up-crossings above the mean elevation in profile, $X$ is the length $(\mathrm{m})$ of profile and $\sigma_{\mathrm{d}}$ is the standard derivation of elevations of profile. For manual photogrammetry, we put the aluminum frame horizontally over the ice surface, the plot is detrended by setting the control points at the $z$ axis of the same values. For automatic photogrammetry, the control field of wooden frame was also laid horizontally over the ice surface, which lowered as the ice melted and maintained a horizontal position between the control field and ice surface. A DEM-based approach enables the roughness frontal area $s$ to be calculated directly for each cardinal wind direction (Smith et al., 2016). The combined roughness frontal area was calculated across the plot, and the ground area occupied by micro-topographic obstacles is $1 \mathrm{~m}^{2}$. We used a DEM-based average $\left(\bar{z}_{0 \_}\right.$DEM $)$of the four cardinal wind directions to represent overall aerodynamic surface roughness. Based on the $30 \mathrm{~min}$ wind direction data at the August one ice cap, the daily upward wind direction DEM-based $z_{0}$ DEM was also estimated at the automatic photogrammetry site. Considering that wind direction changed during the day, in this case we selected the prevailing wind direction to calculate frontal area $s$. The prevailing upwind direction DEM-based $z_{0}$ DEM was applied to calculate turbulent heat flux. Using the Munro (1989) method, $z_{0 \_ \text {profile }}$ was calculated for every profile $(n=1000)$ in both orthogonal directions for each plot at the automatic photogrammetry site.

\subsection{Snow and ice surface energy balance calculation}

The temporal variation in $z_{0}$ at the automatic site was studied from energy balance perspective. The surface heat balance of a melting glacier is given by

$Q_{\mathrm{M}}=Q_{\text {is }}-Q_{\text {os }}+Q_{L}+Q_{E}+Q_{H}+Q_{P}+Q_{G}$,

where $Q_{\mathrm{M}}$ is the heat flux of melting, $Q_{\text {is }}$ is the incoming shortwave radiation, $Q_{\mathrm{os}}$ is the outgoing shortwave radiation, $Q_{L}$ is the net longwave radiation, $Q_{E}$ is the latent heat flux; $Q_{H}$ is the sensible heat flux, $Q_{P}$ is the heat from rain and $Q_{G}$ is subsurface heat flux.

In a horizontally homogeneous and steady surface state, the surface heat fluxes $Q_{E}$ and $Q_{H}$ can be calculated using either the bulk aerodynamic approach or profile method, based on the Monin-Obukhov similarity theory (e.g., Arck and Scherer, 2002; Garratt, 1992; Oke, 1987). In this study, $30 \mathrm{~min}$ observations at $4 \mathrm{~m}$ level and daily upward wind direction DEM-based $z_{0}$ were used to calculate $Q_{E}$ and $Q_{H}$ based on the bulk method. The heat from rain is given by 
Table 2. Control point RMSE for manual and automatic photogrammetry

\begin{tabular}{rrrrrr}
\hline \multicolumn{2}{l}{ Ground control points } & $x$ error $(\mathrm{mm})$ & $y$ error $(\mathrm{mm})$ & $z$ error $(\mathrm{mm})$ & Total error $(\mathrm{mm})$ \\
\hline \multirow{2}{*}{ Automatic } & Point 1 & 0.71 & 5.83 & 6.61 & 5.11 \\
& Point 2 & 0.41 & 1.14 & 0.74 & 0.82 \\
& Point 3 & 0.54 & 4.55 & 2.40 & 2.99 \\
& Point 4 & 0.45 & 0.76 & 1.04 & 0.79 \\
& Average & 0.54 & 3.76 & 3.58 & 3.01 \\
\hline \multirow{6}{*}{ Manual } & Point 2 & 0.62 & 0.43 & 0.81 & 1.11 \\
& Point 4 & 0.44 & 0.27 & 0.43 & 0.67 \\
& Point 5 & 0.18 & 0.47 & 0.85 & 0.99 \\
& Point 7 & 0.66 & 0.39 & 2.97 & 3.07 \\
& Average & 0.52 & 0.40 & 1.65 & 1.78 \\
\hline
\end{tabular}

Table 3. Checkpoint RMSE for manual and automatic photogrammetry.

\begin{tabular}{rrrrrr}
\hline \multicolumn{2}{l}{ Ground checkpoints } & $x$ error $(\mathrm{mm})$ & $y$ error $(\mathrm{mm})$ & $z$ error $(\mathrm{mm})$ & Total error $(\mathrm{mm})$ \\
\hline \multirow{2}{*}{ Automatic } & Point 5 & 2.06 & 4.44 & 7.70 & 5.27 \\
& Point 6 & 0.91 & 3.56 & 1.95 & 2.40 \\
& Point 7 & 0.98 & 3.11 & 2.60 & 2.41 \\
& Average & 1.41 & 3.74 & 4.83 & 3.62 \\
\hline \multirow{6}{*}{ Manual } & Point 1 & 0.30 & 0.19 & 0.39 & 0.52 \\
& Point 3 & 0.79 & 0.37 & 0.69 & 1.12 \\
& Point 6 & 0.28 & 0.83 & 0.90 & 0.77 \\
& Point8 & 0.46 & 0.45 & 0.44 & 0.99 \\
\hline
\end{tabular}

Konya and Matsumoto (2010):

$Q_{P}=\rho_{\mathrm{W}} C_{\mathrm{W}} T_{\mathrm{W}} P_{\mathrm{r}}$,

where $\rho_{\mathrm{W}}$ is the density of water $\left(1000 \mathrm{~kg} \mathrm{~m}^{-3}\right), C_{\mathrm{W}}$ is the specific heat of water $\left(4187.6 \mathrm{~J} \mathrm{~kg}^{-1} \mathrm{~K}^{-1}\right), T_{\mathrm{W}}$ is the wet-bulb temperature $(\mathrm{K})$ and $P_{\mathrm{r}}$ is the rainfall intensity (mm). The subsurface heat flux $Q_{G}$ is estimated from the temperature-depth profile and is given by $Q_{G}=-k_{T} \frac{\partial t^{\prime}}{\partial z^{\prime}}$, where $k_{T}$ is the thermal conductivity, i.e., $0.4 \mathrm{Wm}^{-1} \mathrm{~K}^{-1}$ for old snow and $2.2 \mathrm{~W} \mathrm{~m}^{-1} \mathrm{~K}^{-1}$ for pure ice (Oke, 1987).

In order to calculate $P_{\mathrm{r}}$, we used the air temperatures recorded at the AWS. There is an elevation difference between the study site $(4700 \mathrm{~m})$ and the AWS $(4790 \mathrm{~m})$. Recorded air temperatures were corrected to account for the elevation difference. A lapse rate of $-5.6^{\circ} \mathrm{C} \mathrm{km}^{-1}$ was applied based on observations made nearby (Chen et al., 2014). The ice cap is flat and open terrain so in this case wind speed and relative humidity at the study sites were assumed to be close to those observed at the AWS.

\section{Results}

\subsection{Photogrammetry precision}

We used 17 plots to analyze the horizontal and vertical accuracy of our automatic photogrammetry and 31 plots for our manual photogrammetry. Based on the Agisoft Photoscan processing report, automatic photogrammetry average point density of the final plot point clouds was over 1000000 points $\mathrm{m}^{-2}$. DEMs of $1 \mathrm{~mm}$ resolution were generated at plot scale. The average geo-reference errors fluctuated at around $1 \mathrm{~mm}$ (see Tables 2 and 3). Total root-mean-square error (RMSE) of the automatic control points was $3.0 \pm$ $2.1 \mathrm{~mm}$ and for the checkpoints it was $3.62 \pm 1.6 \mathrm{~mm}$. Vertical error for control points was $3.58 \mathrm{~mm} \pm 3.01 \mathrm{~mm}$ and for the checkpoints it was $4.83 \pm 2.9 \mathrm{~mm}$ (Tables 2 and 3). Standard deviation of control and checkpoint errors are all within $15 \mathrm{~mm}$ (Fig. 4a, c, e). Manually measured average point density of the final plot point clouds was $>6000000$ points $\mathrm{m}^{-2}$. DEM of $1 \mathrm{~mm}$ resolution was generated at plot scale. The RMSE of four control points is $1.78 \pm 1.3 \mathrm{~mm}$ (Table 1 ). The control point vertical accuracy of manual photogrammetry is about $1.65 \pm 1.3 \mathrm{~mm}$. The total RMSE of manual photogrammetry checkpoints is $0.99 \pm 0.3 \mathrm{~mm}$ and the vertical accuracy is $0.66 \pm 0.3 \mathrm{~mm}$ (see Tables 2 and 3). Standard deviation for the $x, y$ and $z$ axes were all within $5 \mathrm{~mm}$ (Fig. $4 \mathrm{~b}, \mathrm{~d}, \mathrm{f}$ ). 

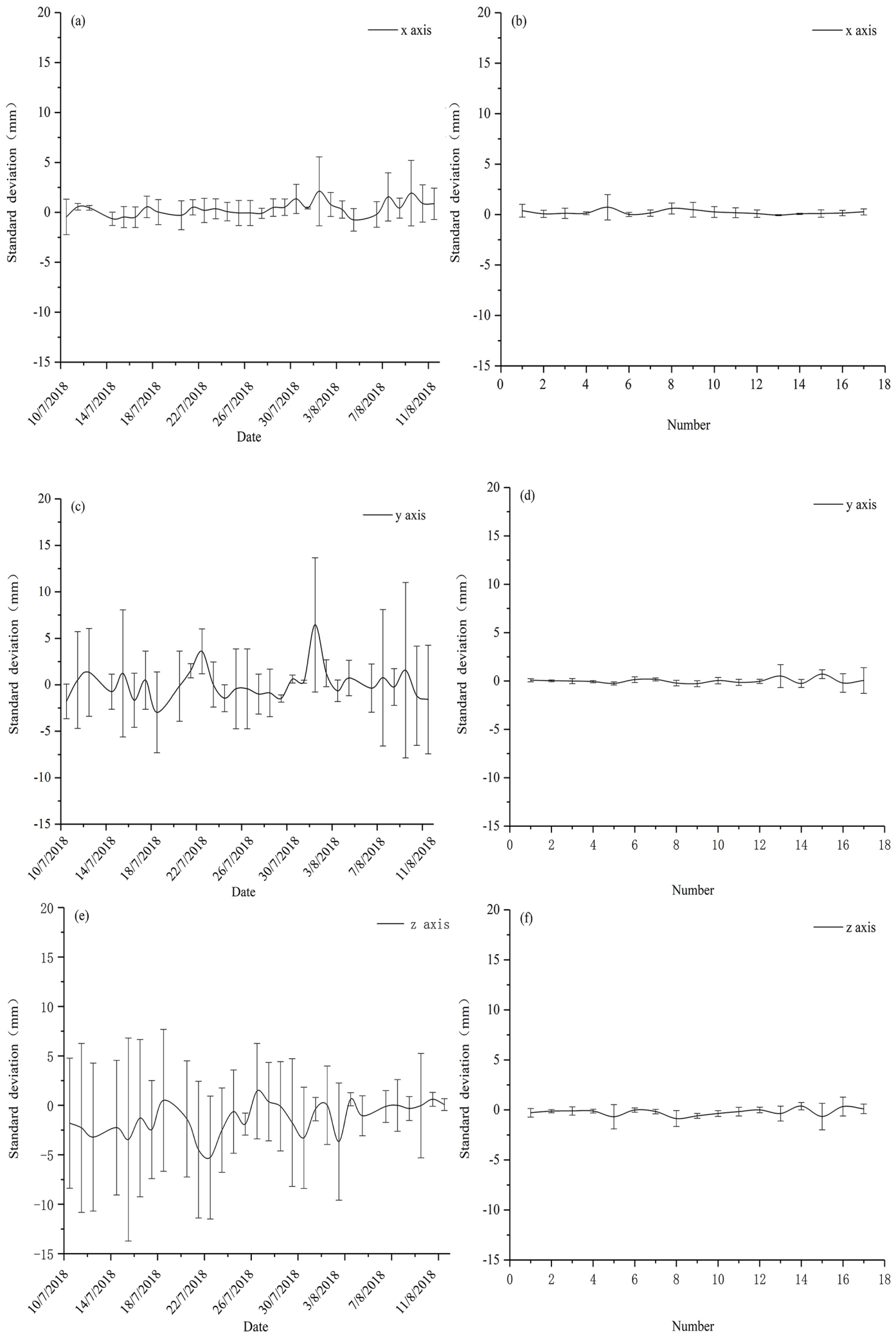

Figure 4. Automatic and manual photogrammetry checkpoint errors. Panels (a), (c) and (e) are automatic photogrammetry standard deviation for the $x, y$ and $z$ axes, respectively. Panels (b), (d) and (f) are manual photogrammetry standard deviation for the $x, y$ and $z$ axes, respectively. 

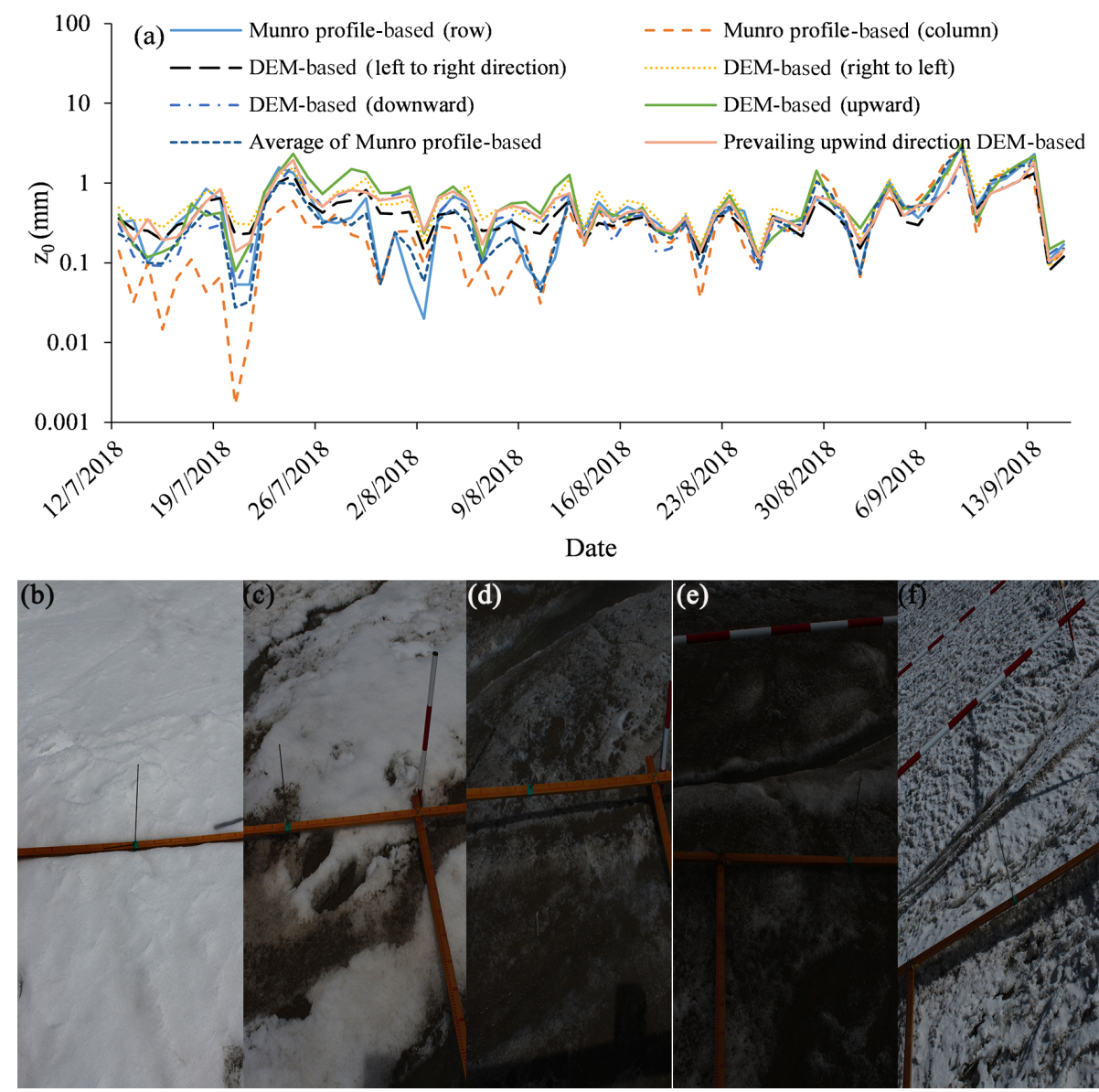

Figure 5. (a) Variation in glacier surface aerodynamic roughness over time at the automatic observation site for the DEM-based and Munro (1989) profile-based approaches. Panel (b) shows a snow-covered surface on 13 July. Panel (c) shows a partially snow-covered surface on 23 July with cryoconite holes. Panels (d) and (e) show a smooth ice surface on 1 and 30 August. Panel (f) shows a rough ice surface on 13 September.

Note that the control and checkpoint errors are larger for the automatic measurements than for the manual ones (see Fig. 4). We believe that this is the case because, rather than using static $f$ stop and exposure times (as in automatic photogrammetry), researchers engaged in manual photogrammetry could adjust exposure time based on ice surface conditions. This allowed production of better quality photos even on cloudy or foggy days. This difference in survey design also caused more precise results for manual than automatic photogrammetry. For the automatic measurements, the camera was moving linearly and the density of tie points was much higher in the foreground compared to the background. For the manual method, photos were taken by surrounding the target area. This type of surface provided a much more robust elevation model and point density.

\subsection{Aerodynamic surface roughness as measured by automatic photogrammetry}

Data for ice surface roughness was collected by the automatic photogrammetry camera site from 12 July to 15 September, a period covering the whole melting season. Profile and DEM data show that $z_{0}$ estimates vary by 2 orders of magnitude over the study period (Fig. 5). The upwind DEM-based data showed a $z_{0}$ DEM varying from 0.1 to $1.99 \mathrm{~mm}$ (mean: $0.55 \mathrm{~mm}$ ). The average of the four cardinal wind directions' DEM data shows a $\bar{z}_{0 \_}$DEM varying from 0.1 to $2.55 \mathrm{~mm}$ (mean: $0.57 \mathrm{~mm}$ ). The average Munro profile-based $z_{0 \_ \text {profile }}$ varied from 0.03 to $2.74 \mathrm{~mm}$ (mean $0.46 \mathrm{~mm}$ ).

At the start of the observation period of 12 July, snow covered the study site. As the snow melted, the ice cap surface $z_{0}$ increased. During this period, $z_{0}$ dropped to around $0.1 \mathrm{~mm}$ due to intermittent snowfall. On 21 July, cryoconites appeared on patches of snow crust, which led to patchy melt. From 21 to 24 July, overall $\bar{z}_{0 \_ \text {DEM }}$ increased from 0.1 to $1.6 \mathrm{~mm}$. By 29 July, snow had disappeared from the study 

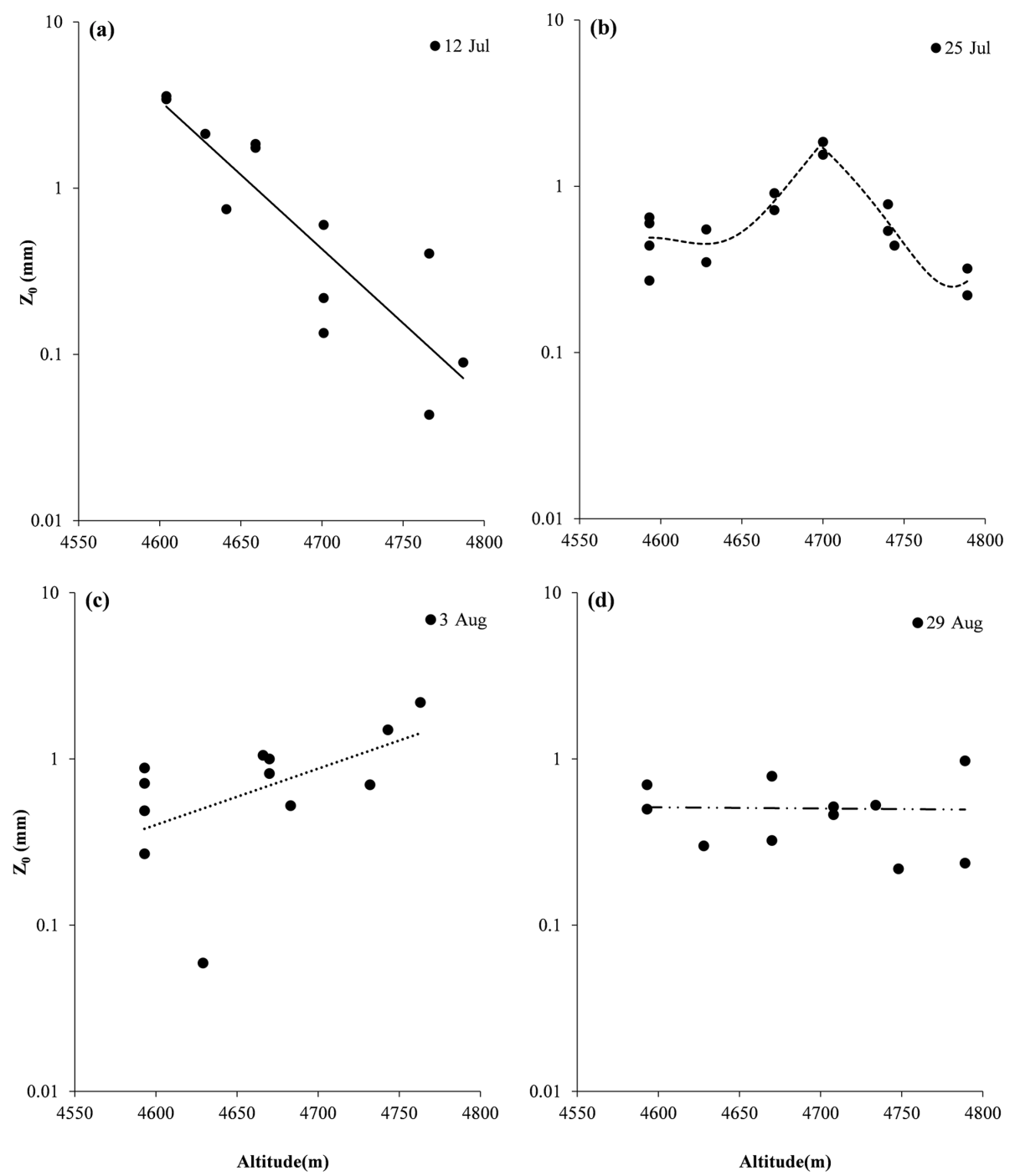

Figure 6. Surface roughness vs. altitude, (a) as observed on 12 July, (b) 25 July, (c) 3 August and (d) 28 August.

site, and $z_{0}$ fluctuated but trended lower. From 29 July to 5 August bare ice covered the whole field of view; $\bar{z}_{0 \_}$DEM ranged from 0.18 to $0.56 \mathrm{~mm}$. From 6 August to 3 September there was intermittent snowfall followed by melting, and $\bar{z}_{0}$ DEM ranged from 0.1 to $1.0 \mathrm{~mm}$. From 4 to 14 September $\bar{z}_{0 \_}$DEM showed an overall increase, reaching a maximum of $2.55 \mathrm{~mm}$ on 8 September. There was intermittent snowfall during this period, which temporarily reduced $\bar{z}_{0 \_ \text {DEM }}$, which then increased thanks to patchy microscale melting. After 14 September, snow covered the whole surface of the glacier and there was no melting and little fluctuation in $z_{0}$.

It should be clear that either $z_{0}$ profile or $z_{0}$ DEM and $\bar{z}_{0 \_}$DEM varied following the same pattern during the melting season. There were two peaks in $z_{0}$, both of which occurred in periods of transition: snow surface turning to ice around 24 July and ice surface turning to snow on 8 September. On 24 July and again on 8 and 13 September, glacier surfaces featured cryoconite holes and snow crust. Both the automatic and manual observations showed the same pattern: maximum $z_{0}$ at the snow-ice transition belt during partially snow-covered periods.

\subsection{Surface roughness as measured by manual photogrammetry}

No wind direction measurements were carried out during manual photogrammetry. In this case, we presented an average of the four cardinal directions to represent ice aerodynamic surface roughness. Analysis indicated that $\bar{z}_{0}$ DEM proved to have an interesting relationship with altitude. $\bar{z}_{0 \_}$DEM was highest in the transition zone between snow cover and ice. This zone moved up the ice cap during the melting season. On 12 July, ice surface roughness decreased from 3.2 to $0.25 \mathrm{~mm}$ as altitude increased (Fig. 6a; $r=$ $0.8429 ; P=0.0006<0.01)$. Near the ice cap terminals at 

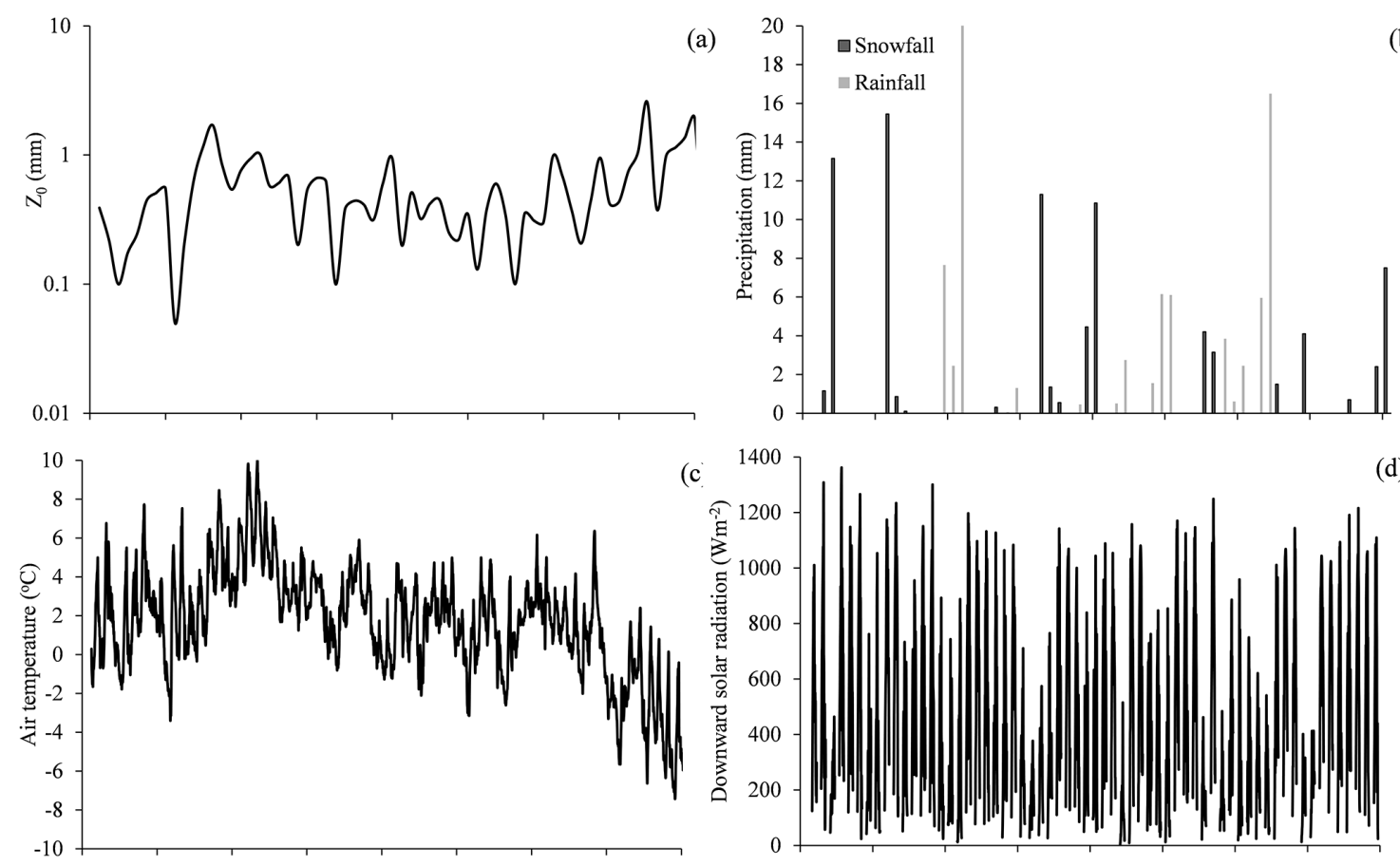

(b)
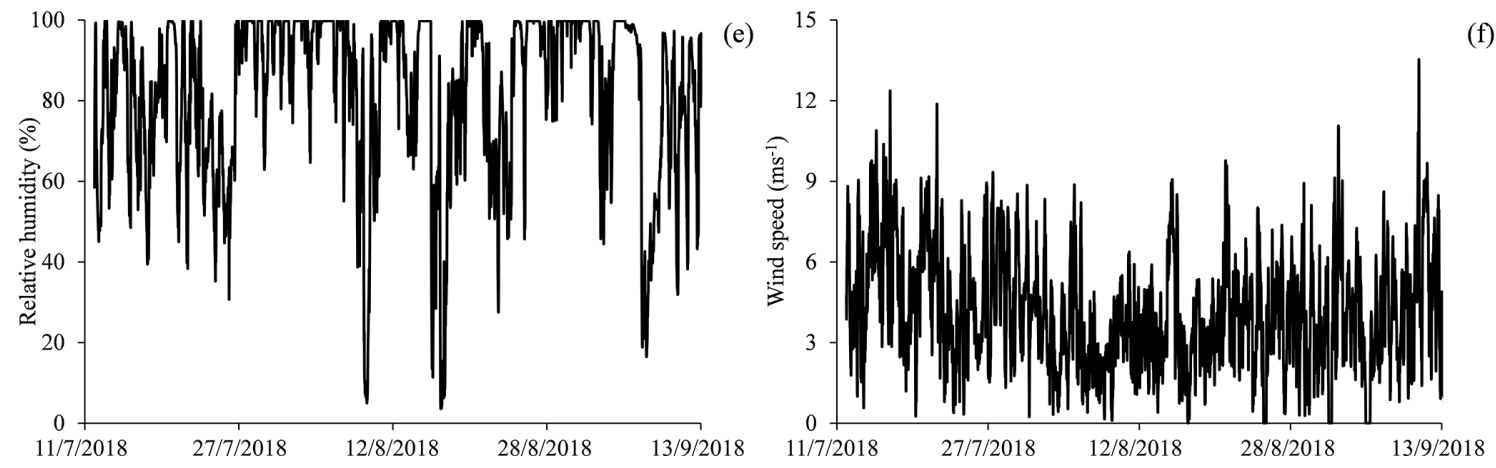

Figure 7. Weather conditions at AWS over study period: (a) precipitation, (b) air temperature, (c) incident solar radiation, (d) relative humidity and (e) wind speed.

$4590 \mathrm{~m}$, the ice surface featured porous snow and ice and many cryoconite holes. As altitude increased, the number of cryoconite holes decreased and snow coverage increased. At $4700 \mathrm{~m}$ the ice surface was predominantly snow covered and only a few small patches were free of snow. On 25 July, ice surface roughness fluctuated between 0.27 to $0.65 \mathrm{~mm}$ at the ice cap terminals $(4593 \mathrm{~m})$. At $\sim 4700 \mathrm{~m}$, roughness increased to $1.85 \mathrm{~mm}$. Above that point, roughness gradually decreased to $0.25 \mathrm{~mm}$ at the ice cap top, which was covered by snow (Fig. 6b).

On 3 August, the August one ice cap was predominantly bare ice and there was scattered snow crust at the ice cap top. The ice surface (terminal to top) showed a heavy deposit of cryoconite. Photogrammetric data collected manually revealed that ice surface roughness increased with altitude (Fig. 6c, $r=0.7$ ). From the terminals to the top of the ice cap, $z_{0}$ varied from 0.06 to $2.2 \mathrm{~mm}$. On 29 August, the ice cap surface roughness showed no significant correlation with altitude (Fig. 6d, $r=-0.03$ ). $\bar{z}_{0}$ DEM varied from 0.2 to $0.98 \mathrm{~mm}$ (Fig. 6d). When we compare the results of the four surveys, we see that ice surface roughness was variable. Maximum $z_{0}$ was seen at the snow and ice transition zone, where the ice surface featured both cryoconite holes and clean snow crust. Snow crust would have inhibited melting; cryoconite would have increased it. It is thus understandable that surface roughness would have been greater in such an area. Bare ice or snow cover both result in comparatively less roughness.

\section{$3.4 \quad z_{0}$ and weather}

Figure 7 compared $\bar{z}_{0 \_ \text {DEM }}$ and corresponding meteorological conditions of precipitation, air temperature, downward solar radiation, relative humidity and wind speed. Detailed analysis indicates snowfall was recorded from 12 to 24 July. 
In general, snowfall reduced roughness if it resulted in a fully snow-covered surface. However, if a patchy, shallow snow cover was formed, it tended to increase $z_{0}$ after a short drop. For example, on 11 and 12 August, two successive sleety days created a patchy snow cover which soon increased $z_{0}$. Between 26 July and 31 August there were 16 rainfall events, which tended to lower ice surface $z_{0}$.

Daily temperatures during the study period ranged from -6.5 to $7.1^{\circ} \mathrm{C}$ (mean: 1.3 ; Fig. $7 \mathrm{c}$ ). It was $1.2^{\circ} \mathrm{C}$ on 11 July. It increased to $3.6^{\circ} \mathrm{C}$ on 24 July (the date when $z_{0}$ was highest). It continued increasing until 29 July, when it reached its highest annual of $7.1^{\circ} \mathrm{C}$. During this period $z_{0}$ continuously declined. From 28 July to the end of August temperatures fluctuated between -0.3 and $5.7^{\circ} \mathrm{C}$ with no evident trend. $\bar{z}_{0 \_ \text {DEM }}$ also fluctuated slightly, showing no obvious trend. In September air temperature quickly dropped from 0.6 to $-6.5^{\circ} \mathrm{C}$. There were large fluctuations in $z_{0}$ during this period. The largest fluctuations appeared when air temperatures dropped from positive to negative.

Daily downward mean solar radiation fluctuated dramatically during the study period due to cloudy and overcast conditions (Fig. 7d). Incident solar radiation fluctuated between 129 and $753 \mathrm{~W} \mathrm{~m}^{-2}$ (mean: $469 \mathrm{~W} \mathrm{~m}^{-2}$ ). From 29 July to the end of August, the weather was cloudy, warm, calm, and

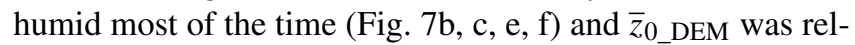
atively stable, except when there was intermittent snowfallinduced fluctuation. After September, the weather again became cold and dry and $z_{0}$ was quite variable.

\subsection{Ice surface energy balance at automatic $z_{0}$ observation study site}

The following section analyzes the changes in surface energy balance at the automatic site. Meteorological observation records allowed us to study the factors that control ice surface roughness. Net radiation varied from -9.7 to 260.2 $\mathrm{W} \mathrm{m}^{-2}$ (mean: $95.3 \mathrm{~W} \mathrm{~m}^{-2}$ ) during the study period. This constituted the largest energy flux affecting glacier surface energy balance. It accounted for $84 \%$ of total incoming flux (Fig. 8). Net radiation was relatively low in the first $13 \mathrm{~d}$ of the study period (mean: $69.3 \mathrm{~W} \mathrm{~m}^{-2}$ ), when the glacier surface was covered with snow. In the succeeding $5 \mathrm{~d}$, net radiation increased to $103.9 \mathrm{~W} \mathrm{~m}^{-2}$. At this time the ice surface exhibited a patchwork of snow, ice, and cryoconite. From 29 July to 5 August the surface of the study site was composed of ice with a dusting of cryoconite. Net radiation reached a height of $183 \mathrm{~W} \mathrm{~m}^{-2}$. There was intermittent snowfall from 6 August to 8 September. Net radiation dropped to a mean $93 \mathrm{~W} \mathrm{~m}^{-2}$. Snow cover then appeared and net radiation dropped to a low of $46 \mathrm{~W} \mathrm{~m}^{-2}$.

Bulk-method-estimated results indicate that sensible heat $\left(Q_{H}\right)$ was the second largest energy flux component of in surface energy balance during the study period (Fig. 8). The sensible heat daily mean varied from -7.1 to $66.3 \mathrm{~W} \mathrm{~m}^{-2}$. It accounted for $-28 \%$ to $32 \%$ (mean: $15 \%$ ) of the net en-

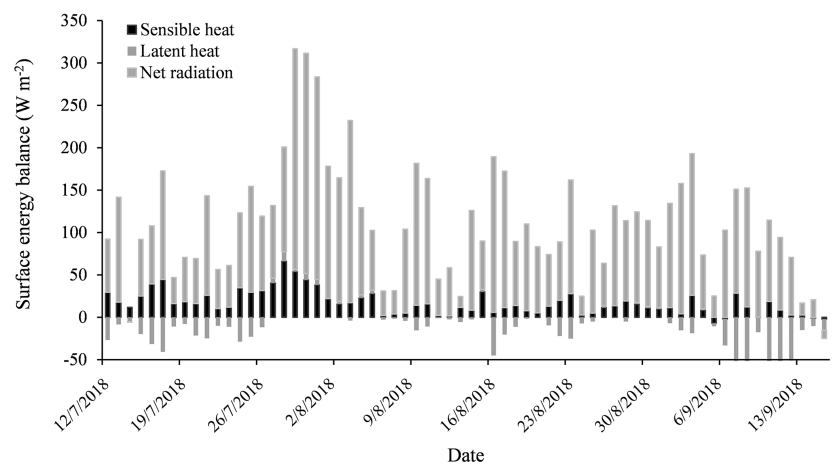

Figure 8. Daily mean energy balance at the middle of the glacier study site, which was close to the automatic photogrammetry site.

ergy flux. Latent heat was generally small throughout the study period. Daily mean of latent heat varied from -80.1 to $11.1 \mathrm{~W} \mathrm{~m}^{-2}$ (mean: $-13.2 \mathrm{~W} \mathrm{~m}^{-2}$ ). It accounts for a mere $0.9 \%$ for the total incoming flux. It was negative from 11 to 26 July when the ice surface was snow covered. After 26 July the latent heat was mainly positive in the following $10 \mathrm{~d}$ (the ice surface was pure ice or partially snow covered). From 6 August to the end of the study period (15 September) it was predominantly negative.

From 25 July to 5 August rainfall energy varied from 0 to $11.7 \mathrm{~W} \mathrm{~m}^{-2}$ (mean: $0.3 \mathrm{~W} \mathrm{~m}^{-2}$ ). Rainfall accounted for a mere $0.2 \%$ of total incoming flux. One event accounted for much of the total: on 28 July a $31 \mathrm{~mm}$ rainfall event added a flux of $11.7 \mathrm{~W} \mathrm{~m}^{-2}$, which resulted in visible smoothing of the ice surface (Fig. 9). Compared to other energy components, $Q_{G}$ was very small, with a daily mean of $-0.65 \mathrm{~W} \mathrm{~m}^{-2}$ and a maximum and minimum of -0.4 and $-2.1 \mathrm{~W} \mathrm{~m}^{-2}$, respectively.

\subsection{Modeled vs. observed surface ablation}

Based on the previously listed measurements of energy fluxes, we calculated the probable surface ablation at the automatic photogrammetry site. We took into account observed net radiation, bulk-method-calculated turbulent heat fluxes, heat from rainfall and subsurface heat flux. There was good agreement between the model and observed results (Fig. 10).

Figure 11 shows the relationship between estimated daily upward wind direction DEM-based $z_{0}$ DEM and the main energy flows. Scatter diagrams showed a positive relationship between $z_{0}$ _DEM and net shortwave radiation (Fig. 11a, $r=$ 0.1 ) and a significant negative relationship between $z_{0 \_}$DEM and net longwave radiation (Fig. 11b, $r=-0.35$ ), Graphing $z_{0}$ DEM vs. bulk-method-estimated latent heat showed a significant negative exponential relationship (Fig. 11d, $r=$ $-0.35)$. The scatter diagram showed no significant relationship between $z_{0 \_ \text {DEM }}$ and the bulk-method-estimated sensible heat (Fig. 11c). The average of the Munro profile-based $z_{0}$ profile, DEM-based $\bar{z}_{0 \_}$DEM and the main energy items are 


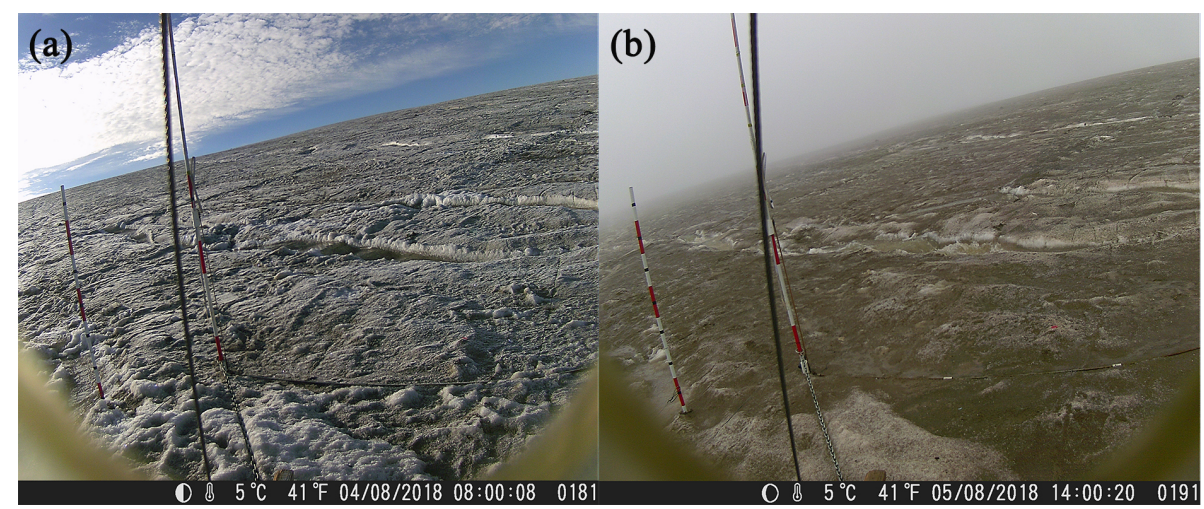

Figure 9. Ice surface overview at the automatic photogrammetry site before and after a strong rainfall event captured by an automatic digital infrared hunting video camera: (a) photograph taken before the rainfall event on 4 August of 2018 and (b) photograph taken after the strong rainfall event on 5 August of 2018.

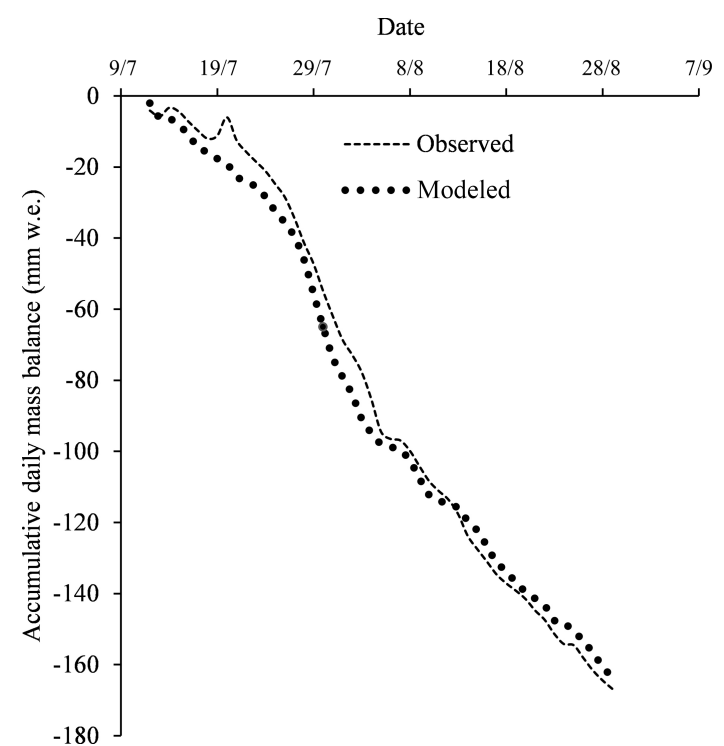

Figure 10. Comparison of observed daily mass balance and modeled daily mass balance. Mass balance measurements were taken from 12 July to 29 August. Measurements of surface lowering were converted into water equivalents using density values.

also analyzed. Scatter diagrams showed a significant negative relationship between $z_{0}$ profile and net longwave radiation

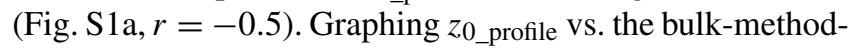
estimated latent heat showed a significant negative exponential relationship (Fig. S1d, $r=-0.69$ ). The scatter diagram showed no significant relationship between $z_{0 \_ \text {profile }}$ and the

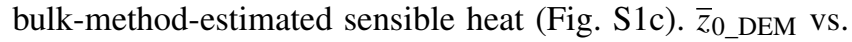
the bulk-method-estimated latent heat showed a significant negative exponential relationship (Fig. S2d, $r=-0.44$ ). In the scatter diagrams between $\bar{z}_{0 \_}$DEM and net shortwave radiation, the bulk-method-estimated sensible heat showed no significant relationship.
Table 4. The lagged correlation between $z_{0}$ and the main energy items during the melting season; the sensible heat and latent heat were calculated here based on the bulk method.

\begin{tabular}{lcrrrrr}
\hline$z_{0 \_ \text {profile }}$ & $n$ & $\left(Q_{\text {is }}-Q_{\mathrm{os}}\right)$ & $Q_{L}$ & $Q_{E}$ & $Q_{H}$ & $L_{\mathrm{S}}$ \\
\hline Lag 0 & 64 & 0.143 & $-0.309^{*}$ & $-0.614^{*}$ & -0.088 & $-0.578^{*}$ \\
Lag 1 & 63 & 0.131 & $-0.346^{*}$ & $-0.646^{*}$ & -0.137 & $-0.572^{*}$ \\
Lag 2 & 62 & -0.022 & -0.113 & $-0.356^{*}$ & $-0.307^{*}$ & $-0.585^{*}$ \\
Lag 3 & 61 & -0.144 & 0.051 & $-0.193^{*}$ & $-0.283^{*}$ & $-0.523^{*}$ \\
Lag 4 & 60 & -0.142 & -0.241 & -0.016 & -0.013 & -0.205 \\
\hline$n=$ the number of samples, ${ }^{*} P<0.05$. & & & &
\end{tabular}

Because net shortwave radiation and turbulent heat fluxes were the main energy fluxes affecting ice surface roughness, we calculated a turbulent heat proportion index:

$L_{\mathrm{S}}=\left(Q_{H}+Q_{E}+Q_{P}\right) /\left(Q_{\text {is }}-Q_{\mathrm{os}}\right)$.

Note that aerodynamic surface roughness on days when snow fell was strongly affected by the amount of the snowfall. If we exclude snowfall days and snow-covered period, we see a significant exponential relationship between ice surface $z_{0}$ DEEM and $L_{\mathrm{S}}$ (Fig. 12a, $r=-0.34$ ). The scatter diagrams showed a significant exponential relationship between ice surface $z_{0 \_ \text {profile }}$ and $L_{\mathrm{S}}$ and net longwave radiation (Fig. 12c, $r=-0.69) . \bar{z}_{0 \_ \text {DEM }}$ vs. $L_{\mathrm{S}}$ also showed a significant exponential relationship (Fig. 12b, $r=-0.46$ ). Scatter diagrams in Fig. 12 also showed $z_{0}$ did not keep decreasing when $L_{\mathrm{S}}$ was above 0.2 . $z_{0 \_ \text {DEM }}, z_{0 \_ \text {profile }}$ and $\bar{z}_{0 \_}$DEM were around $0.56 \pm 0.21,0.33 \pm 0.03$ and $0.6 \pm 0.26 \mathrm{~mm}$, respectively.

The $z_{0}\left(z_{0 \_}\right.$DEM and $z_{0 \_ \text {profile }} \bar{z}_{0 \_}$DEM $)$vs. $L_{\mathrm{S}}$ graph indicates that when turbulence and rainfall heat increased, aerodynamic surface roughness decreased. As soon as $L_{\mathrm{S}}$ is above 0.2 , the ice surface will not keep smoothing and $z_{0}$ sustains its lowest stage. Time series correlation of all main energy items and $z_{0}$ profile were performed. Table 4 shows an example of the lagged correlations between $z_{0 \_ \text {profile }}$ and five variables. The $z_{0}$ and net shortwave radiation displayed a positive correlation with 0 to $1 \mathrm{~d}$ lag time. The $z_{0}$ response to 

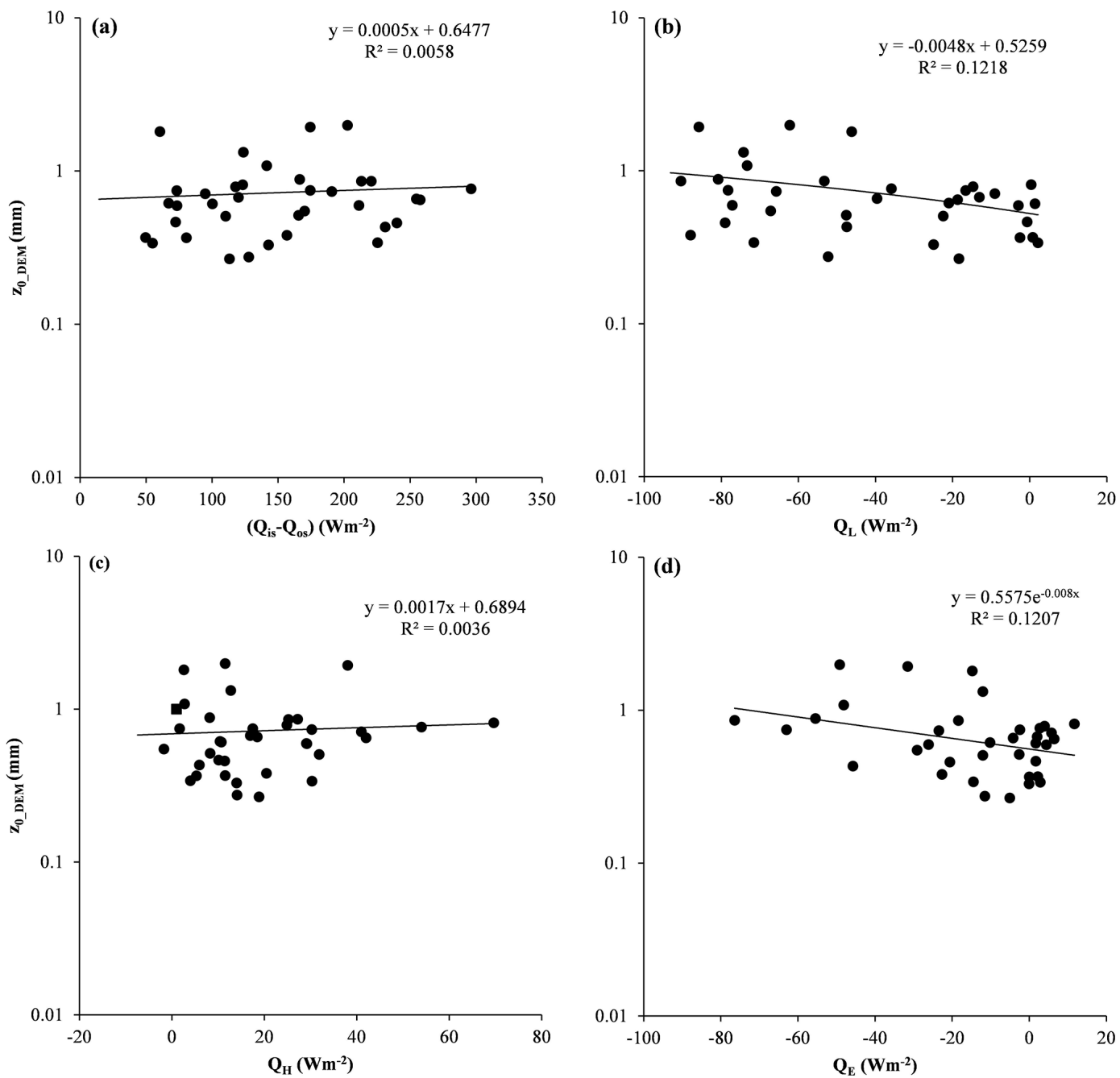

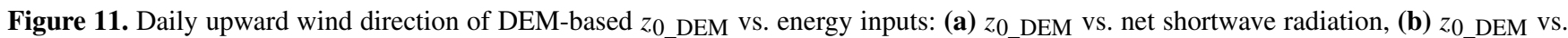
net longwave radiation, (c) $z_{0}$ DEM vs. bulk-method-calculated sensible heat and (d) $z_{0}$ DEM vs. bulk-method-calculated latent heat.

$Q_{E}$ with a correlation of -0.6 showed a lag of 0 to $1 \mathrm{~d}$. The $z_{0 \_ \text {profile }}$ also had a negative relationship with $Q_{L}$ with no lag or $1 \mathrm{~d}$ lag time. The $z_{0}$ profile response to $L_{\mathrm{S}}$ with a correlation of -0.58 was with a lag of 0 to $2 \mathrm{~d}$. A total of 0 to $2 \mathrm{~d}$ lag time gives an indication of the effort limitations of the main energy items over ice surface $z_{0}$. In other words, a sunny and cold day facilitates rough ice surfaces and warm and cloudy days tend to produce a smoother ice surface. When net shortwave radiation is higher and latent and sensible heat are smaller, $z_{0}$ tends to be higher for the next $2 \mathrm{~d}$. When net shortwave radiation is smaller, as on cloudy days, any snowfall or rainfall is usually associated with smaller $z_{0}$ for the following $2 \mathrm{~d}$. Under a negative $Q_{\mathrm{M}}$, the surface $z_{0}$ would not be affected by melting process.

\section{Discussion}

\subsection{Automatic and manual photogrammetric methods}

Photogrammetric techniques such as Structure from Motion (SfM) (James and Robson, 2012) and Multi-view Stereo (MVS) represent low-cost options for acquiring highresolution topographic data. Such approaches require relatively little training and are extremely inexpensive (Westoby et al., 2012; Fonstad et al., 2013; Passalacqua et al., 2015). We used both automatic and manual photogrammetric methods to sample spatial and temporal $z_{0}$ variation at the August one ice cap. Adjustments to exposure time based on ice surface conditions and survey design of the area surrounding the target made the manual photogrammetry more precise than automatic photogrammetry (Tables 2 and 3 ). However, precision is not always the major concern. The glacier surface was a harsh (even punishing) environment for the researchers do- 

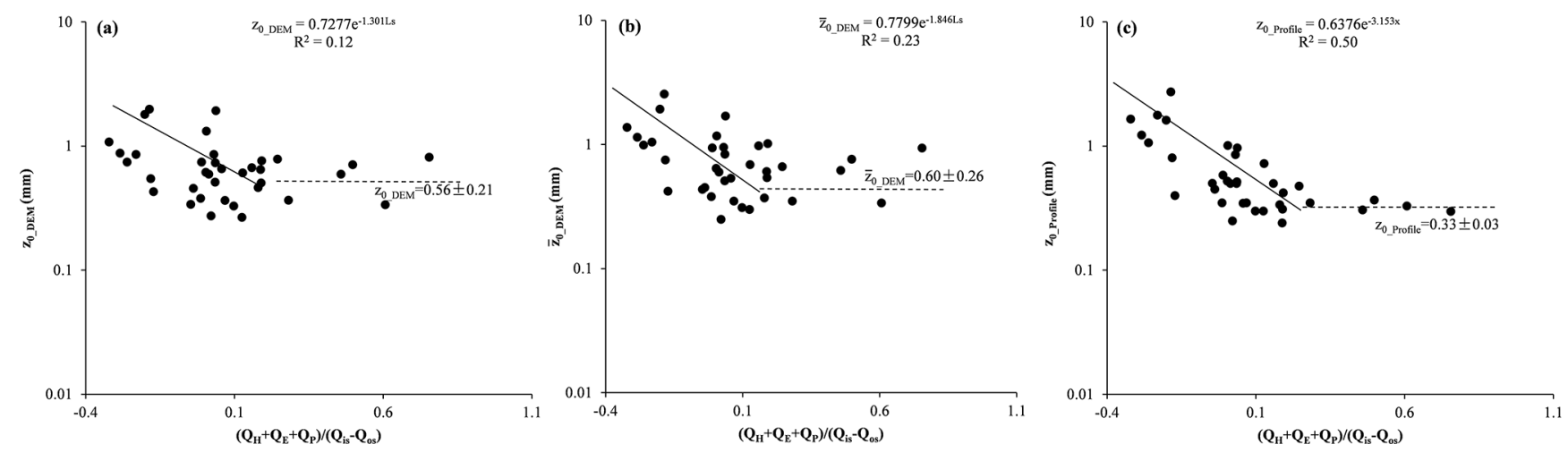

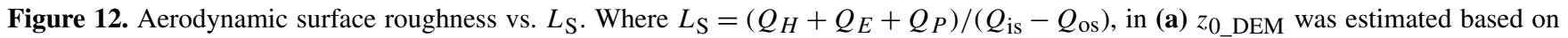
DEM-based prevailing upwind direction, in (b) $\bar{z}_{0}$ DEM was the average of the four cardinal wind directions' $z_{0}$ in order to represent overall aerodynamic surface roughness and in (c) $z_{0}$ profile was the average of two orthogonal directions $z_{0}$.

ing manual photogrammetry. In addition, manual photogrammetry took much longer. Automatic methods reduced hours of field work, spared researchers and produced nearly continuous data. Cloudy or frosty weather affected automatic photogrammetry exposures, and heavy snowfalls resulted in a textureless surface. Nevertheless, it is likely that photogrammetry techniques will continue to improve and that these drawbacks may be mitigated.

\subsection{Spatial and temporal variability of $z_{0}$}

Previous studies of glacier surfaces roughness have rarely covered the whole glacier, from the terminals to the top of the ice cap, in one melting season (Föhn, 1973; Smeets et al., 1999; Denby and Smeets, 2000; Greuell and Smeets, 2001; Albert and Hawley, 2002; Brock et al., 2006; Smeets and Van den Broeke, 2008; Smith et al., 2016). This whole-glacier study allowed us to follow the movement of the transition zone, where snow was melting and exposing ice, from the terminals to the top of the ice cap. The transition zone moved up as the melting season proceeded, thus roughening the surface of the glacier and raising $z_{0}$. At the start of the melting season, snow cover first disappeared, leaving an ice surface at the terminal end of the August one ice cap, i.e., at the lower altitude. This newly exposed surface was rougher $\left(z_{0}\right.$ was higher) than on the upper part of glacier, which was still snow covered (see the black line in Fig. 6a for $z_{0}$ distribution at different altitudes). As the snowline shifted to higher altitudes, ice surface increased, as did $z_{0}$ (see the dashed black curve in Fig. 6b). As the melting continued, the snow and ice transition belt reached the top of glacier (see the dotted curve in Figure 6c). When the ice cap was completely free of snow, $z_{0}$ and elevation were no longer correlated (see the dotted-dashed line in Fig. 6d). In summary, maximum $z_{0}$ was recorded at the cross-glacier transition zone between snow and ice. This zone shifted from lower altitude to higher altitude, from the terminals to the top of the ice cap, during the melting season. The spatial pattern of $z_{0}$ distribution affected turbulent fluxes. The transition zone had maximum $z_{0}$, and the zone also migrated across much of the glacier, highlighting the importance of transient surface characteristics.

Micro-topography, wind profile and eddy covariance methods generate a wide range of $z_{0}$ values for snow and ice surfaces (Grainger and Lister, 1966; Munro, 1989; Bintanja and Broeke, 1995; Schneider, 1999; Hock and Holmgren, 2005; Brock et al., 2006; Andreas et al., 2010; Gromke et al., 2011). In this study, $z_{0 \_ \text {profile }}, z_{0 \_ \text {DEM }}$ and $\bar{z}_{0 \_ \text {DEM }}$ showed similar variation pattern during the melting season. The difference of $z_{0 \_ \text {profile }}, z_{0 \_ \text {DEM }}$, and $\bar{z}_{0 \_ \text {DEM }}$ were within 1 order of magnitude. The latent and sensible heat calculated by $z_{0 \_ \text {profile }}, z_{0 \_ \text {DEM }}$ and $\bar{z}_{0 \_ \text {DEM }}$ were highly relevant among these methods. The automatic photogrammetry estimated $z_{0}$ for snow-covered surfaces ranged from 0.1 to 0.55 . New snowfall at the snow surface in July formed the lowest $z_{0}$ values. Previous studies have shown that freshly fallen snow is subject to rapid destructive metamorphism (McClung and Schaerer, 2006), which can dramatically change the roughness of fresh snow surfaces (Fassnacht et al., 2009b). Our study showed that $z_{0}$ followed an increasing trend during the melting season. Intermittent snowfall first decreased snow surface $z_{0}$, which then began to increase as the snow surface deteriorated. In the data from Clifton et al. (2008), snow surface $z_{0}$ was estimated at between 0.17 to $0.6 \mathrm{~mm}$ in a wind tunnel experiment. In an analysis of ultrasonic anemometer recorder data over snow-covered sea ice, Andreas et al. (2010) found $z_{0}$ values ranging from $10^{-2}$ to $10^{1} \mathrm{~mm}$. In a wind tunnel experiment of fresh snow with nodrift conditions, Gromke et al. (2011) estimated $z_{0}$ to be between 0.17 to $0.33 \mathrm{~mm}$, with no apparent dependency on the friction velocity. Our snow surface data showed that $z_{0}$ values fluctuated between 0.03 to $0.55 \mathrm{~mm}$, consistent with some of those wind tunnel studies. The scatter of $z_{0}$ data reported in some studies is quite large, with a range of $10^{-2}$ to $10^{1} \mathrm{~mm}$. The result may be attributed to the occurrence of snow drift, a transitional rough-flow regime and large uncertainties in the 
estimation of friction velocities that propagate to the computation of $z_{0}$ (Andreas et al., 2010; Gromke et al., 2011). In contrast, the small scatter in our data was induced only by the natural variability of snow surface roughness.

For patchy snow-covered ice surfaces, $z_{0}$ varied from 0.5 to $2.6 \mathrm{~mm}$ and ice surface $z_{0}$ varied from 0.24 to $1.1 \mathrm{~mm}$. During the melting season, there were no blowing snow events and snow surface $z_{0}$ was relatively smaller than in patchy snow-covered surface or ice surface. Ice surface $z_{0}$ was generally larger than snow surface and smaller than patch snow-covered surface. Our results match values reported in studies reporting results ranging from 0.1 to $6.9 \mathrm{~mm}$ in Qilian mountain glaciers (Guo et al., 2018; Sun et al., 2018). Our results showed that $z_{0}$ reached its maximum at the end of the summer melt, which matched wind profile measurements by Smeets and Broeke (2008).

The aerodynamic surface roughness is influenced by both the boundary layer and the surface. In this study, the microtopographic estimated aerodynamic surface roughness only considers surface topography at plot scale but its variability is influenced by its surrounding topography and the boundary layer. Thus, the results of $z_{0}$ estimated in this study still need to be validated by wind tower or eddy covariance observations. However, micro-topographic roughness metrics are a very strong proxy for $z_{0}$ (e.g., Nield et al., 2013), so we have much more confidence in the temporal and spatial variability presented by this work.

\subsection{Effects of surface energy balance components on aerodynamic surface roughness}

Aerodynamic roughness is associated with the geometry of ice roughness elements (Kuipers, 1957; Lettau, 1969; Munro, 1989). Surface geometry roughness develops due to local melt inhomogeneities in melting season. In earlier works, researchers argued that a variety of ablation forms, such as sun cups, penitents, cryoconite holes or dirt cones, are formed by the sun (Matthes, 1934; Lliboutry, 1954; McIntyre, 1984; Rhodes et al., 1987; Betterton, 2000). These ablation forms develop in regions with bright sunlight and cold, dry weather conditions are apparently required (Rhodes et al., 1987). These structures are observed to decay if the weather is cloudy or very windy (Matthes, 1934; Lliboutry, 1954; McIntyre, 1984).

The August one ice cap dust concentrations are high in the melting season. Cryoconites are unevenly distributed over the ice surface, leading to differential absorption of shortwave radiation at microscale. This process results in the roughening of the ice surface, a process that enhances turbulent heat exchange across the atmospheric boundary layerice interface. When the air temperature is above $0{ }^{\circ} \mathrm{C}$, the ice surface keeps melting. The turbulent heat smooths the ice surface, increases the cryoconite concentration over the ice surface and decreases ice surface albedo, enhancing shortwave radiation absorption (Fig. 9). This roughening and smoothing process makes ice surface $z_{0}$ fluctuate at around $0.56 \mathrm{~mm}$ as long as the air temperature is above $0^{\circ} \mathrm{C}$. When the temperature drops below $0{ }^{\circ} \mathrm{C}$, bright sunlight and dry weather shutdown the ice surface smoothing process. The shortwave radiation induces even rougher ice and larger $z_{0}$ until snow covers the ice surface. At the August one ice cap, the turbulent heat contributes a small portion of incoming energy, but the smoothing ice surface process decreases ice surface albedo and seems to enhance ice surface shortwave radiation. The $z_{0}$ fluctuation in the melt season is similar, with cryoconite holes developing when the radiative flux is dominant and decaying when turbulent heat is dominant (McIntyre, 1984; Takeuchi et al., 2018). The glacier surface energy balance components vs. $z_{0}$ analysis in this study confirm that the main energy items of net shortwave radiation and turbulent heat flux affect the same-day $z_{0}$ and following $2 \mathrm{~d}$ of $z_{0}$. This study found an exponential relationship between $z_{0}$ and $L_{S}$. The delicate role of $z_{0}$ played in the ice surface balance is still not fully known. Further comparative studies are needed to investigate the $z_{0}$ variation through eddy covariance and profiling methods and DEM-based $z_{0}$ estimation.

\section{Conclusions}

Manual and automatic measurements of snow and ice surface roughness at the August one ice cap showed spatial and temporal variation in $z_{0}$ over the melting season. Manual measurements, taken from the terminals to the top of the ice cap, show that the nature of the surface cover features are correlated with $z_{0}$ rank in the following order: transition region $>$ pure ice area or pure snow area. The transition region forms a zone of maximum $z_{0}$, which shifts over the melting season from the terminals to the top of the ice cap. The observed $z_{0}$ vs. energy items analysis indicated that $L_{\mathrm{S}}$ (turbulent heat index) was also an important determinant of ice aerodynamic surface roughness.

Aerodynamic surface roughness is a major parameter in calculations of glacier surface turbulent heat fluxes. In previous studies investigators used a constant $z_{0}$ value for the whole surface of the glacier. This study captures a much smaller-scale variation in spatial and temporal glacier surface aerodynamic roughness through automatic and manual photogrammetric observations. Such close observation of variation in $z_{0}$ certainly enhanced the accuracy of the surface energy balance models developed in the course of this study.

This study was carried out at an ice cap with a neat ordering of its annual layers. The August one ice cap moved slowly, no crevasses were formed over the ice cap and channels were not considered in this study. In this case, a more moderate variation in $z_{0}$ was estimated than would be found for debris-covered glaciers (Miles et al., 2017; Quincey et al., 2017). Uneven or heterogeneous ice surfaces such as sastrugi, crevasses, channels and penitents could greatly affect ice surface aerodynamic surface roughness, and it would be 
hard to estimate its $z_{0}$ based on a profile method. SfM estimation of $z_{0}$ might be a good choice at a macroscale. In the accumulation season, more attention would need to be paid to spatial and temporal variations in $z_{0}$, as $z_{0}$ is a key parameter for sublimation calculation during this period. Studies have indicated that the Lettau (1969) approach calculated $z_{0}$ dependent on plot scale and resolution. In this study, we only select $1 \mathrm{~m} \times 1 \mathrm{~m}$ scale at $1 \mathrm{~mm}$ resolution to study spatial and temporal variability. Further comparative studies of $z_{0}$ are needed at different scales and resolutions.

Data availability. All of the observation and model input and output data presented in this study are available upon request to the corresponding author (Rensheng Chen, crs2008@1zb.ac.cn).

Author contributions. JL and RC designed the study and wrote the paper. JL and $\mathrm{CH}$ carried out field-based manual photogrammetry observations.

Competing interests. The authors declare that they have no conflict of interest.

Acknowledgements. We thank the editor and the two reviewers for their insightful comments and ideas that improved the paper.

Financial support. This research has been supported by the National Natural Science Foundation of China (grant nos. 41877163 and 41671029).

Review statement. This paper was edited by Valentina Radic and reviewed by Joshua Chambers and Evan Miles.

\section{References}

Albert, M. R. and Hawley, R. L.: Seasonal changes in snow surface roughness characteristics at Summit, Greenland: implications for snow and firn ventilation, Ann. Glaciol., 35, 510-514, doi:10.3189/172756402781816591, 2002.

Andreas, E. L.: Parameterizing scalar transfer over snow and ice: A review, J. Hydrometeorol., 3, 417-432, 2002.

Andreas, E. L., Persson, P. O. G., Jordan, R. E., Horst, T. W., Guest, P. S., Grachev, A. A., and Fairall, C. W.: Parameterizing turbulent exchange over sea ice in winter, J. Hydrometeorol., 11, 87-104, doi:10.1175/2009JHM1102.1, 2010.

Arck, M., and Scherer, D.: Problems in the determination of sensible heat flux over snow, Geogr. Ann., 84, 157-169, doi:10.1111/1468-0459.00170, 2002.

Betterton, M. D.: Formation of structure in snowfields: Penitentes, suncups, and dirt cones, Phys. Rev. E, 63, 056129, doi:10.1103/PhysRevE.63.056129, 2000.
Bintanja, R. and Van den Broeke, M.: Momentum and scalar transfer-coefficients over aerodynamically smooth Antarctic surfaces, Bound.-Lay. Meteorol., 74, 89-111, doi:10.1007/BF00715712, 1995.

Brock, B. W., Willis, I. C., and Sharp, M. J.: Measurement and parameterization of aerodynamic roughness length variations at Haut Glacier d'Arolla, Switzerland, J. Glaciol., 52, 1-17, 2006.

Chen, R. S., Song, Y. X., Kang, E. S., Han, C. T., Liu, J. F., Yang, Y., Qing, W. W., and Liu, Z. W.: A Cryosphere-Hydrology Observation System in a Small Alpine Watershed in the Qilian Mountains of China and Its Meteorological Gradient, Arct. Antarct. Alp. Res., 46, 505-523, doi:10.1657/1938-4262-46.2.505, 2014.

Clifton, A., Manes, C., Rueedi, J. D., Guala, M., and Lehning, M.: On shear-driven ventilation of snow, Bound.-Lay. Meteorol., 126, 249-261, doi:10.1007/s10546-007-9235-0, 2008.

Denby, B. and Smeets, C.: Derivation of turbulent flux profiles and roughness lengths from katabatic flow dynamics, J. Appl. Meteorol., 39, 1601-1612, 2000.

Denby, B. and Snellen, H.: A comparison of surface renewal theory with the observed roughness length for temperature on a melting glacier surface, Bound.-Lay. Meteorol., 103, 459-468, 2002.

Dong, W. P., Sullivan, P. J., and Stout, K. J.: Comprehensive study of parameters for characterizing three-dimensional surface topography I: Some inherent properties of parameter variation, Wear, 159, 161-171, 1992.

Fassnacht, S. R., Stednick, J. D., Deems, J. S., and Corrao, M. V.: Metrics for assessing snow surface roughness from digital imagery, Water Resour. Res., 45, W00D31, doi:10.1029/2008wr006986, 2009a.

Fassnacht, S. R., Williams, M., and Corrao, M.: Changes in the surface roughness of snow from millimetre to metre scales, Ecol. Complex., 6, 221-229, doi:10.1016/j.ecocom.2009.05.003, 2009b.

Fitzpatrick, N., Radić, V., and Menounos, B.: A multi-season investigation of glacier surface roughness lengths through in situ and remote observation, The Cryosphere, 13, 1051-1071, https://doi.org/10.5194/tc-13-1051-2019, 2019.

Föhn, P. M. B.: Short-term snow melt and ablation derived from heat-and mass-balance measurements, J. Glaciol., 12, 275-289, 1973.

Fonstad, M. A., Dietrich, J. T., Courville, B. C., Jensen, J. L., and Carbonneau, P. E.: Topographic structure from motion: a new development in photogrammetric measurement, Earth Surf. Proc. Land., 38, 421-430, doi:10.1002/esp.3366, 2013.

Garratt, J. R.: The Atmospheric Boundary Layer, Cambridge University Press, New York, 1992.

Grainger, M. and Lister, H.: Wind speed, stability and eddy viscosity over melting ice surfaces, J. Glaciol., 6, 101-127, 1966.

Greuell, W. and Smeets, P.: Variations with elevation in the surface energy balance on the Pasterze (Austria), J. Geophys. Res.Atmos., 106, 31717-31727, 2001.

Gromke, C., Manes, C., Walter B, Lehning, M., and Guala, M.: Aerodynamic roughness length of Fresh snow, Bound.-Lay. Meteorol., 141, 21-34, doi:10.1007/s10546-011-9623-3, 2011.

Guo, S. H., Chen, R. S., Liu, G. H., Han, C. T., Song, Y. X., Liu, J. F., Yang, Y., Liu, Z. W., Wang, X. Q., and Liu, X. J.: Simple Parameterization of Aerodynamic Roughness Lengths and the Turbulent Heat Fluxes at the Top of Midlatitude August-One Glacier, 
Qilian Mountains, China, J. Geophys. Res.-Atmos., 123, 1206612080, doi:10.1029/2018JD028875, 2018.

Guo, W., Liu, S., Xu, J., Wu, L., Shangguan, D., Yao, X., Wei, J., Bao, W., Yu, P., Liu, Q., and Jiang, Z.: The second Chinese glacier inventory: data, methods and results. J. Glaciol., 61, 357372, doi:10.3189/2015jog14j209, 2015.

Hock, R. and Holmgren, B.: A distributed surface energybalance model for complex topography and its application to Storglaciären, Sweden, J. Glaciol., 51, 25-36, doi:10.3189/172756505781829566, 2005.

Irvine-Fynn, T., Sanz-Ablanedo, E., Rutter, N., Smith, M., and Chandler, J.: Measuring glacier surface roughness using plotscale, close-range digital photogrammetry, J. Glaciol., 60, 957969, doi:10.3189/2014JoG14J032, 2014.

James, M. R. and Robson, S.: Mitigating systematic error in topographic models derived from UAV and ground-based image networks, Earth Surf. Proc. Land., 39, 1413-1420, doi:10.1002/esp.3609, 2014.

James, M. R., Robson, S., and Smith, M. W.: 3-D uncertaintybased topographic change detection with structure-from-motion photogrammetry: precision maps for ground control and directly georeferenced surveys, Earth Surf. Proc. Land., 42, 1769-1788, doi:10.1002/esp.4125, 2017.

James, M. and Robson, S.: Straightforward reconstruction of 3D surfaces and topography with a camera: Accuracy and geoscience application, J. Geophys. Res.-Earth, 117, F03017, doi:10.1029/2011JF002289, 2012.

Javernick, L., Brasington, J., and Caruso, B.: Modeling the topography of shallow braided rivers using Structure-fromMotion photogrammetry, Geomorphology, 213, 166-182, doi:10.1016/j.geomorph.2014.10.006, 2014.

Konya, K. and Matsumoto, T.: Influence of weather conditions and spatial variability on glacier surface melt in Chilean Patagonia, Theor. Appl. Climatol., 102, 139-149, 2010.

Kuipers, H.: A relief meter for soil cultivation studies, Neth. J. Agr. Sci., 5, 255-262, 1957.

Lacroix, P., Legrésy, B., Coleman, R., Dechambre, M., and Rémy, F.: Dual-frequency altimeter signal from Envisat on the Amery ice-shelf, Remote Sens. Environ., 109, 285-294, doi:10.1016/j.rse.2007.01.007, 2007.

Lacroix, P., Legrésy, B., Langley, K., Hamran, S., Kohler, J., Roques, S., Rémy, F., and Dechambre, M.: In situ measurements of snow surface roughness using a laser profiler, J. Glaciol., 54, 753-762, doi:10.3189/002214308786570863, 2008.

Lehning, M., Bartelt, P., Brown, B., and Fierz, C.: A physical SNOWPACK model for the Swiss avalanche warning: Part III: meteorological forcing, thin layer formation and evaluation, Cold Reg. Sci. Technol., 35, 169-184, doi:10.1016/S0165232X(02)00072-1, 2002.

Lettau, H.: Note on aerodynamic roughness parameter estimation the basis of roughness element description, J. Appl. Meteorol., 8, 828-832, 1969.

Lliboutry, L.: The origin of penitents, J. Glaciol., 2, 331-338, https://doi.org/10.3189/S0022143000025181, 1954.

Manninen, T., Anttila, K., Karjalainen, T., and Lahtinen, P.: Automatic snow surface roughness estimation using digital photos, J. Glaciol., 58, 993-1007, doi:10.3189/2012JoG11J144, 2012.

Matthes F. E.: Ablation of snow-fields at high altitudes by radiant solar heat, T. AGU, 15, 380-385, 1934.
McClung, D. and Schaerer, P. A.: The avalanche handbook, The Mountaineers Books, Seattle, WA, 2006.

McIntyre, N. F.: Cryoconite hole thermodynamics, Can. J. Earth Sci., 21, 152-156, 1984.

Miles, E. S., Steiner, J. F., and Brun, F.: Highly variable aerodynamic roughness length $\left(z_{0}\right)$ for a hummocky debriscovered glacier, J. Geophys. Res.-Atmos., 122, 8447-8466, doi:10.1002/2017JD026510, 2017.

Munro, D. S.: Surface roughness and bulk heat transfer on a glacier: comparison with eddy correlation, J. Glaciol., 35, 343-348, doi:10.3189/S0022143000009266, 1989.

Nield, J. M., King, J., Wiggs G. F. S., Leyland, J., Bryant, R. G., Chiverrell, R. C., Darby, S. E., Eckardt, F. D., Thomas, D. S. G., Vircavs, L. H., and Washington, R.: Estimating aerodynamic roughness over complex surface terrain, J. Geophys. Res.Atmos., 118, 12948-12961, doi:10.1002/2013JD020632, 2013.

Oke, T. R.: Boundary layer climates, Routledge, London, 1987.

Oveisgharan, S. and Zebker, H. A.: Estimating snow accumulation from InSAR correlation observations, IEEE T. Geosci. Remote, 45, 10-20, doi:10.1109/TGRS.2006.886196, 2007.

Passalacqua, P., Belmont, P., Staley, D. M., Simley, J. D., Arrowsmith, J. R., Bode, C. A., Crosby, C., DeLong, S. B., Glenn, N. F., Kelly, S. A., Lague, D., Sangireddy, H., Schaffrath, K., Tarboton, D., Wasklewicz, T., and Wheaton, J. M.: Analyzing high resolution topography for advancing the understanding of mass and energy transfer through landscapes: A review, Earth-Sci. Rev., 148, 174-193, doi:10.1016/j.earscirev.2015.05.012, 2015.

Qing, W., Han, C. T., and Liu, J.: Surface energy balance of Bayi Ice Cap in the middle of Qilian Mountains, China, J. Mt. Sci., 15, 1229-1240, https://doi.org/10.1007/s11629-017-4654-y, 2018

Quincey, D., Smith, M., Rounce, D., Ross, A., King, O., and Watson, C.: Evaluating morphological estimates of the aerodynamic roughness of debris covered glacier ice, Earth Surf. Proc. Land., 42, 2541-2553, doi:10.1002/esp.4198, 2017.

Rees, W. G.: A rapid method of measuring snow-surface profiles, J. Glaciol., 44, 674-675, doi:10.3189/S0022143000002197, 1998.

Rees, W. G. and Arnold, N. S.: Scale-dependent roughness of a glacier surface: implications for radar backscatter and aerodynamic roughness modelling, J. Glaciol., 52, 214-222, doi:10.3189/172756506781828665, 2006.

Rhodes, J. J., Armstrong, R. L., and Warren, S. G.: Mode of formation of "ablation hollows" controlled by dirt content of snow, J. Glaciol., 33, 135-139, 1987.

Rippin, D. M., Pomfret, A., and King, N.: High resolution mapping of supra-glacial drainage pathways reveals link between micro-channel drainage density, surface roughness and surface reflectance, Earth Surf. Proc. Land., 40, 1279-1290, doi:10.1002/esp.3719, 2015.

Rounce, D. R., Quincey, D. J., and McKinney, D. C.: Debriscovered glacier energy balance model for Imja-Lhotse Shar Glacier in the Everest region of Nepal, The Cryosphere, 9, 2295 2310, https://doi.org/10.5194/tc-9-2295-2015, 2015.

Schneider, C.: Energy balance estimates during the summer season of glaciers of the Antarctic Peninsula, Global Planet. Change, 22, 117-130, doi:10.1016/S0921-8181(99)00030-2, 1999.

Smeets, C. J. P. P., and Van den Broeke, M. R.: Temporal and spatial variations of the aerodynamic roughness length in the ablation zone of the Greenland ice sheet, Bound.-Lay. Meteorol., 128, 315-338, doi:10.1007/s10546-008-9291-0, 2008. 
Smeets, C. J. P. P., Duynkerke, P. G., and Vugts, H. F.: Turbulence characteristics of the stable boundary layer over a mid-latitude glacier. Part II: Pure katabatic forcing conditions, Bound.-Lay. Meteorol., 97, 73-107, 2000.

Smeets, C., Duynkerke, P., and Vugts, H.: Observed wind profiles and turbulence fluxes over an ice surface with changing surface roughness, Bound.-Lay. Meteorol., 92, 101-121, 1999.

Smith, M. W., Quincey, D. J., Dixon, T., Bingham, R. G., Carrivick, J. L., Irvine-Fynn, T. D. L., and Rippin, D. M.: Aerodynamic roughness of glacial ice surfaces derived from highresolution topographic data, J. Geophys. Res.-Earth, 121, 748766, doi:10.1002/2015JF003759, 2016.

Smith, M. W.: Roughness in the earth sciences, Earth-Sci. Rev., 136, 202-225, 2014.

Steiner, J. F., Litt, M., Stigter E. E., Shea, J., Bierkens M. F. P., and Immerzeel W. W.: The importance of turbulent fluxes in the surface energy balance of a debris-covered glacier in the Himalayas, Front. Earth Sci., 6, 144, doi:10.3389/feart.2018.00144, 2018.
Sun, W. J., Qin, X., Wang, Y. T., Chen, J. Z., Du, W. T., Zhang, T., and Huai, B. J.: The response of surface mass and energy balance of a continental glacier to climate variability, western Qilian Mountains, China, Clim. Dynam., 50, 3557-3570, doi:10.1007/s00382-017-3823-6, 2018.

Takeuchi, N., Sakaki, R., Uetake, J., Nagatsuka, N., Shimada, R., Niwano, M., and Aoki, T.: Temporal variations of cryoconite holes and cryoconite coverage on the ablation ice surface of Qaanaaq Glacier in northwest Greenland, Ann. Glaciol., 59, $21-$ 30, doi:10.1017/aog.2018.19, 2018.

Wendler, G. and Streten, N.: A short term heat balance study on a coast range glacier, Pure Appl. Geophys., 77, 68-77, 1969.

Westoby, M. J., Brasington, J., Glasser, N. F., Hambrey, M. J., and Reynolds, J. M.: "Structure-from-Motion" photogrammetry: A low-cost, effective tool for geoscience applications, Geomorphology, 179, 300-314, doi:10.1016/j.geomophy.2012.08.021, 2012. 